\title{
¿Más o menos desiguales? Una revisión sobre la desigualdad de los ingresos a nivel global, regional y nacional
}

\author{
Verónica Amarante y Maira Colacce
}

\section{Resumen}

En este artículo se presenta una discusión, desde diferentes miradas, sobre cómo ha evolucionado la desigualdad de los ingresos. Se considera la desigualdad global del ingreso sobre la base de múltiples evidencias recientes, que señalan una relativa estabilidad del elevado nivel de desigualdad. Los principales cambios surgen de los movimientos de China y la India. En los países desarrollados, la tendencia ha sido hacia mayores niveles de desigualdad en los últimos tres decenios. También ha sido así en los países en desarrollo, con la excepción de América Latina en el último decenio. Esta región se analiza en detalle; en términos globales, los ingresos se volvieron más igualitarios entre 2002 y 2014, debido fundamentalmente a la caída de la desigualdad dentro de los países. La desigualdad se ha reducido en la mayoría de ellos, aunque las últimas mediciones dan indicios de una detención en este proceso de descenso.

\section{Palabas clave}

Crecimiento económico, ingresos, distribución del ingreso, igualdad, medición, países desarrollados, países en desarrollo, China, América Latina

\section{Clasificación JEL}

D31, D61

Autoras

Verónica Amarante es Directora de la Oficina de la Comisión Económica para América Latina y el Caribe (CEPAL) en Montevideo. Correo electrónico: verónica. amarante@cepal.org.

Maira Colacce es Consultora en la Oficina de la CEPAL en Montevideo. Correo electrónico: maira.colacce@gmail.com. 


\section{Introducción}

Una pregunta en apariencia sencilla y que en la actualidad sin duda se ha formulado varias veces en diversos ámbitos se refiere a si la desigualdad económica es mayor en nuestros días que hace algunas décadas. En otras palabras: ¿las sociedades modernas avanzan hacia mayores niveles de igualdad económica, o el nivel de vida de los individuos tiende a diferenciarse de manera creciente? La respuesta a una pregunta de tal amplitud es compleja y conviene abordarla desde diversos ángulos, si se aspira a lograr una respuesta que a la vez sea abarcadora y concreta. En este artículo se busca brindar elementos para responder esta pregunta, sintetizando la evidencia reciente que surge de diversos estudios internacionales sobre la temática y profundizando en algunos aspectos específicos de la discusión, sobre los que se presenta nueva evidencia. Para ello, se recorren diferentes caminos, aunque se analiza siempre la desigualdad del ingreso o el consumo de las personas a partir de encuestas de hogares. Eso implica dejar de lado otros enfoques, como la desigualdad de la riqueza o el análisis de otras fuentes de información que permitan identificar de forma más precisa los ingresos de las personas más ricas.

En primer lugar, se revisa la evidencia existente en relación con la desigualdad global y su evolución. Esto comprende considerar el ingreso o el consumo de todos los individuos del mundo, como si no existieran las fronteras políticas de los países. Dado que las diferencias entre los individuos surgen de la desigualdad entre los países y la desigualdad dentro de ellos, el estudio se complementa con la discusión sobre las experiencias nacionales. En relación con estas últimas, se distingue entre la evolución de la desigualdad en los países desarrollados y en los países en desarrollo, ya que la dinámica en ambas situaciones se ha diferenciado en años recientes. Dentro de las experiencias de los países en desarrollo, se profundiza en la situación de China, que tiene una incidencia muy alta en términos de la desigualdad global y a la vez ha tenido una evolución nacional con particularidades que la hacen interesante. Por último, se considera en detalle la situación de América Latina en su conjunto y de sus países de forma individual, los que en su mayoría mostraron un descenso de la desigualdad durante el último decenio, contrariamente a lo que sucedía en el mundo desarrollado, aunque la última información disponible parece indicar una meseta en dicho proceso. El objetivo final del artículo es presentar una discusión actualizada sobre la desigualdad de los ingresos con una mirada amplia, buscando brindar un panorama general sobre la situación mundial y regional. En el análisis se abordan distintos períodos temporales. En el caso de la desigualdad global y la de los países en desarrollo y los desarrollados, se considera todo el período abarcado por la bibliografía revisada, mientras que el análisis de la región se concentra en el último decenio, cuando se revierte la tendencia creciente de la desigualdad en la región.

\section{Desigualdad global}

A medida que aumenta la integración entre los países, también se incrementa la movilidad de los factores entre las fronteras, así como la influencia de las condiciones de vida de la población de otros países en las percepciones y aspiraciones de la población de cada país. Todos estos aspectos hacen que la desigualdad más allá de las fronteras nacionales se torne relevante. Surge así la preocupación por la desigualdad global, es decir, la que se observa entre todos los habitantes del mundo. En sus orígenes, la literatura sobre desigualdad global estuvo motivada por la necesidad de evaluar en qué medida, aun cuando la globalización hubiera implicado aumentos de la desigualdad en el interior de los países, podría haber implicado también una reducción de las diferencias entre los individuos del mundo, en caso de que los países más pobres (y más poblados) hubieran crecido más rápido que los más ricos (y menos poblados). Estos estudios también tenían por objeto analizar si las reglas que gobiernan las interacciones entre los países ricos y los pobres afectan la desigualdad global.

¿Más o menos desiguales? Una revisión sobre la desigualdad de los ingresos a nivel global, regional y nacional 
Existen diversas justificaciones de por qué estudiar la desigualdad global. Según Anand y Segal (2008), se pueden destacar en primer lugar los argumentos morales o éticos, dado que las disparidades entre los ingresos individuales a nivel global pueden ser consideradas injustas, y esto sienta las bases para el análisis de qué tan diferente es el ingreso de los individuos considerados globalmente y no en función de su nacionalidad. En segundo lugar, la desigualdad global puede ser el factor explicativo de ciertos fenómenos, como la migración internacional o el poder de negociación en las instituciones internacionales. Por último, la evolución de los niveles de desigualdad a escala mundial resulta interesante para analizar el poder predictivo de ciertas teorías: de acuerdo con la teoría de crecimiento neoclásica, en el largo plazo deberíamos observar una convergencia de los ingresos entre los países, e incluso entre los individuos, mientras que, en la teoría de la dependencia, se predice divergencia.

Antes de avanzar, es importante distinguir entre los diferentes conceptos de desigualdad global que se manejan en la literatura, para entender sus implicancias y usos. Milanovic (2005) y Anand y Segal (2008) definen cuatro conceptos de desigualdad a nivel mundial, que se diferencian por los elementos que se consideran: las unidades de análisis (países o personas), la unidad de medida (ingreso total, per cápita o del hogar), y el ponderador de los países (uniforme o dependiente de su población o ingreso).

En el "concepto cero" se aborda la desigualdad entre los países ordenándolos de acuerdo a su ingreso total y dando a cada uno el mismo peso. Este concepto es el más apropiado para analizar cuestiones de geopolítica y acceso a los mercados. En el "concepto uno" se estima la desigualdad entre los países considerando el ingreso per cápita de cada uno y ponderándolos de igual modo. Sirve para estudiar la validez empírica de los postulados de convergencia o divergencia planteados por los modelos de crecimiento. Ninguno de estos dos conceptos será utilizado en el análisis que se presenta a continuación. En el "concepto dos" se considera la desigualdad entre todos los individuos del mundo si su ingreso fuese el ingreso per cápita de su país. Este concepto es conocido como la desigualdad entre los países y puede obtenerse de igual modo que el concepto uno, pero ponderando los países de acuerdo al tamaño de su población. En el "concepto tres", que se adopta en el análisis que se presenta a continuación, se mide la desigualdad entre los individuos considerando el ingreso per cápita del hogar al que pertenecen. Esta medida es el análogo mundial de la distribución que suele utilizarse para medir la desigualdad dentro de los países, es decir, sería equivalente a suponer que no existen fronteras. En lo que resta de esta sección, cuando se haga referencia a la desigualdad global, se estará considerando este último indicador.

En varios artículos recientes se ha analizado este último concepto de desigualdad global y su evolución. Tres de esos trabajos comparten algunos criterios metodológicos que posibilitan su comparación. Lamentablemente, dado que se basan en información de encuestas de hogares, los cálculos más antiguos corresponden a la década de 1980. Se trata de los estudios de Lakner y Milanovic (2016), Niño-Zarazúa, Roope y Tarp (2014), y Anand y Segal (2015), cuya sistematización brinda un panorama actualizado del estado del arte en la temática ${ }^{1}$. En estos estudios se utiliza información de encuestas de hogares de cada país para estimar el perfil de distribución del ingreso y del ingreso promedio de los países. Se consideran cuantiles de la distribución del ingreso de cada país (generalmente ventiles), se imputa a cada cuantil el ingreso per cápita promedio y se construye una base de datos con los cuantiles de los distintos países del mundo². Para que los ingresos

\footnotetext{
1 Una revisión de los estudios previos sobre la temática puede encontrarse en Anand y Segal (2008). Se destaca también el trabajo de Bourguignon (2015), que no se reseña en esta oportunidad dado que en él se toman algunas decisiones metodológicas diferentes que no permiten compararlo con los resultados restantes. En particular, en Bourguignon (2015) se reescalan los ingresos per cápita de las encuestas de hogares de modo que coincidan en promedio con el ingreso per cápita que se indica en las cuentas nacionales.

2 En los trabajos que se reseñan, la cobertura en términos de población supera el 90\% de la población mundial en los últimos años, aunque hay brechas mayores en los primeros años de los estudios, cuando la información de las encuestas de hogares no era generalizada en todos los países.
} 
sean comparables, se los convierte a un numerario común, utilizando índices de paridad del poder adquisitivo (PPA) $)^{3}$.

Un primer resultado que comparten los tres estudios es que el nivel de desigualdad global es muy alto, comparable al de los países de mayor desigualdad del mundo, cuando no superior. Como se observa en el cuadro 1, el índice de Gini global varía entre 67 y 72,2, según el año y la estimación. No se observan grandes movimientos del indicador en el período considerado: los tres estudios analizados presentan variaciones de aproximadamente 2 puntos en un lapso de dos decenios. Los autores señalan que las diferencias son lo suficientemente pequeñas como para sospechar que no son significativas desde el punto de vista estadístico, y lo que se destaca es más bien la estabilidad de la medición ${ }^{4}$. En una actualización del trabajo de Lakner y Milanovic (2016), se incorpora información hasta 2011 y se concluye que, en los últimos años, se produce una caída importante del índice de Gini global, que desciende a 64 (Milanovic, 2016).

Cuadro 1

Índice de Gini global, años seleccionados

(En porcentajes)

\begin{tabular}{lccc}
\hline & Lakner y Milanovic (2016) & $\begin{array}{c}\text { Niño-Zarazúa, Roope } \\
\text { y Tarp (2014) }\end{array}$ & Anand y Segal (2015) \\
\hline $1985-1988$ & 69,4 & 70,2 & 72,2 \\
\hline $1993-1995$ & 69,1 & 70,4 & 71,9 \\
\hline 1998 & 68,4 & - & 71,5 \\
\hline $2002-2003$ & 68,7 & - & 71,9 \\
\hline $2005-2008$ & 67 & 68,1 & 70,5 \\
\hline
\end{tabular}

Fuente: Elaboración propia, sobre la base de C. Lakner y B. Milanovic, "Global income distribution: from the fall of the Berlin Wall to the Great Recession", World Bank Economic Review, vol. 30, № 2, Washington, D.C., Banco Mundial, 2016 ; M. Niño-Zarazúa, L. Roope y F. Tarp, "Global interpersonal inequality: trends and measurement", WIDER Working Paper, N 2014/004, Helsinki, Instituto Mundial de Investigaciones de Economía del Desarrollo (UNU-WIDER), 2014; y S. Anand y P. Segal, "The global distribution of income", Handbook of Income Distribution, A. Atkinson y F. Bourguignon (eds.), vol. 2, Amsterdam, Elsevier, 2015.

Con el objetivo de comprender mejor los movimientos subyacentes a esta aparente estabilidad, es posible distinguir dos componentes dentro de la desigualdad: la que se da entre los países y la que se observa en el interior de ellos. A tales efectos, se calcula una medida de la desigualdad del ingreso entre los países que implica suponer que el ingreso de cada persona es el ingreso promedio de su país. La diferencia entre la desigualdad global y esa desigualdad entre los países es el componente que se le asigna a la desigualdad dentro de los países ${ }^{5}$. Los tres estudios reseñados coinciden en señalar que la desigualdad entre los países es más alta que la que se observa dentro de ellos. Lakner y Milanovic (2016) señalan que, si en 2008 se iguala el ingreso per cápita promedio de los países, pero se mantiene la distribución del ingreso dentro de cada uno, la desigualdad global caería aproximadamente el $77 \%$, mientras que, si se iguala el ingreso dentro de los países y se mantienen las diferencias entre ellos, la desigualdad global caería tan solo el $24 \%$.

Mientras que la desigualdad dentro de los países crece en el período analizado, la desigualdad entre los países cae. En otras palabras, el aumento de la desigualdad dentro de los países fue

3 En los tres casos se utilizan los factores de conversión a dólares de 2005 del Banco Mundial.

4 Dado que se consideran encuestas de diferentes fuentes con diversas metodologías de muestreo, no se pueden calcular errores estándar de la medición global.

5 Esta medida de desigualdad entre los países es un promedio ponderado de la desigualdad dentro de cada país. En el caso de utilizar el índice de Theil (GE(1)) como medida de desigualdad, se pondera a partir de la participación de cada país en los ingresos globales. Cuando el indicador de desigualdad seleccionado es el desvío medio del ingreso logarítmico (GE(0)), se pondera cada país según su participación en la población total. 
compensado con creces por la fuerte caída de la desigualdad entre ellos, lo que condujo a leves caídas del indicador de desigualdad global. La diferente evolución de la desigualdad entre los países y dentro de ellos provoca importantes cambios en la composición del índice global: a modo de ejemplo, Niño-Zarazúa, Roope y Tarp (2014) estiman que, en 1985, el componente asociado a la desigualdad dentro de los países representaba el 20,4\% del índice global, mientras que, en 2005, dicho componente casi se duplica y representa el $38,8 \%$. Estos movimientos se deben sobre todo a lo ocurrido en China y, en menor medida, en la India. En ambos países se observa simultáneamente un aumento de la desigualdad y un fuerte crecimiento de los ingresos promedio. Dado el imponente peso que los dos tienen en la población total, sus movimientos hacen que crezca la desigualdad dentro de los países a nivel global y se reduzca la desigualdad entre ellos. El ejercicio de simulación que presentan estos autores muestra que, si estos países hubiesen crecido al ritmo que lo hicieron pero no se hubiese modificado su distribución del ingreso en relación con 1975, la desigualdad global hubiese caído más de lo que efectivamente cayó (un 3\% adicional). Por otro lado, dichos autores observan que, si la población de China y la India hubiese aumentado al ritmo que lo hizo pero se hubiesen mantenido los ingresos y la distribución de 1975, la desigualdad en 2005 hubiese aumentado de forma significativa (12\%).

La importancia de China y la India se evidencia también cuando se analiza gráficamente cómo evoluciona la distribución del ingreso global (véase el gráfico 1). Se destacan dos grandes movimientos: el corrimiento hacia la derecha de la distribución en el período considerado (que implica un aumento de los ingresos) y el cambio en la forma de la distribución, donde la doble moda tiende a desaparecer de manera paulatina.

\section{Gráfico 1}

Distribución global del ingreso, años seleccionados ${ }^{a}$

(En densidad del ingreso logarítmico y en dólares PPA de 2005)

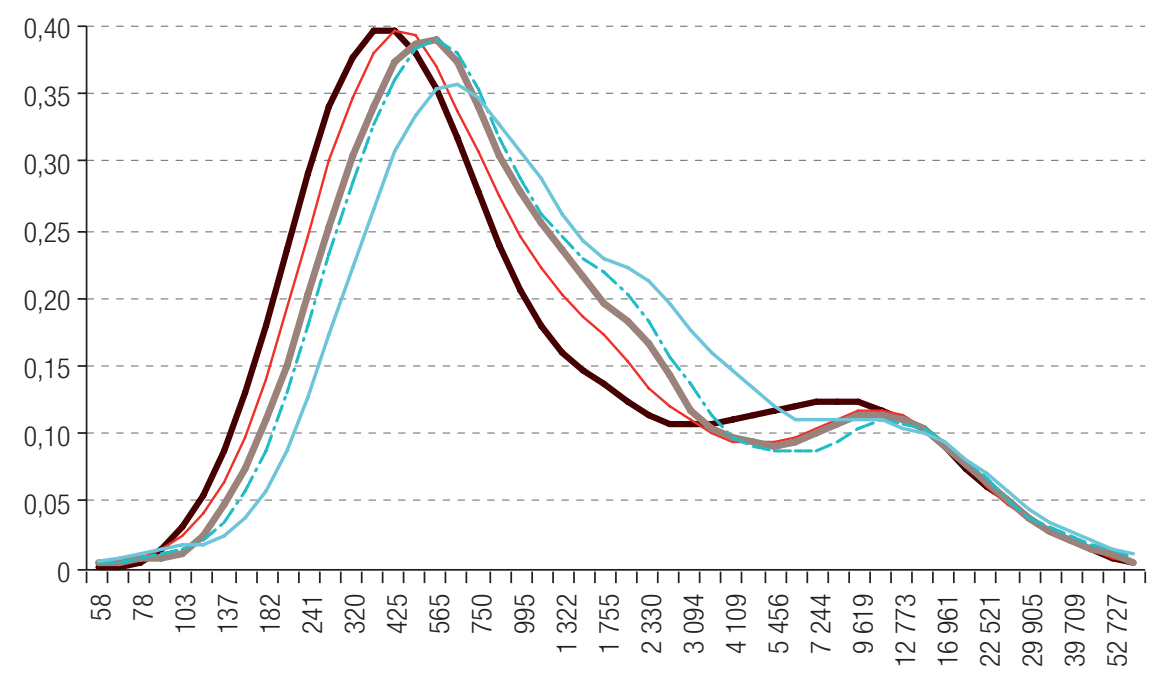

— $1988-1993-1998--2003-2008$

Fuente: C. Lakner y B. Milanovic, "Global income distribution: from the fall of the Berlin Wall to the Great Recession", World Bank Economic Review, vol. 30, № 2, Washington, D.C., Banco Mundial, 2016.

a En escala logarítmica y ponderado por la población.

b Paridad del poder adquisitivo.

Lakner y Milanovic (2016) señalan que ambos movimientos pueden explicarse casi totalmente por el cambio observado en China y, en menor medida, en la India. Tanto China como la India se corren hacia la derecha en la distribución (véase el gráfico 2), dejando a África Subsahariana en el extremo izquierdo. 


\section{Gráfico 2}

Distribución global del ingreso, años seleccionados ${ }^{a}$

(En densidad del ingreso logarítmico y en dólares PPA ${ }^{\mathrm{b}}$ de 2005)

A. 1988

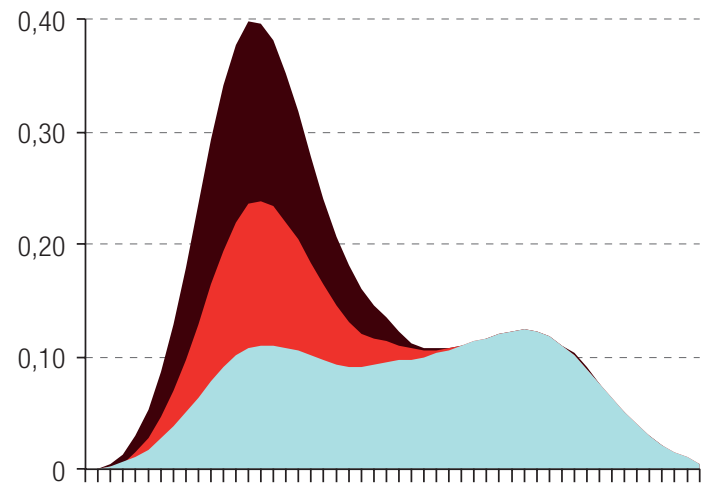

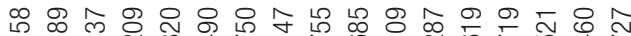

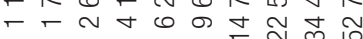

\section{1998}

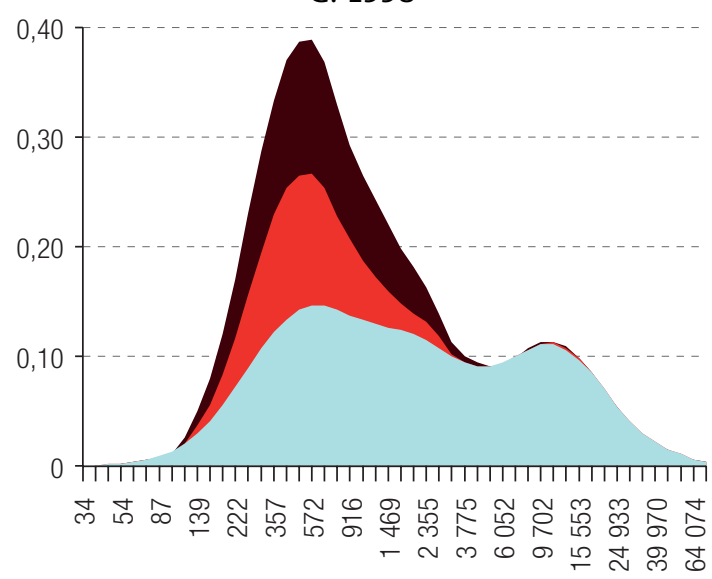

B. 1993

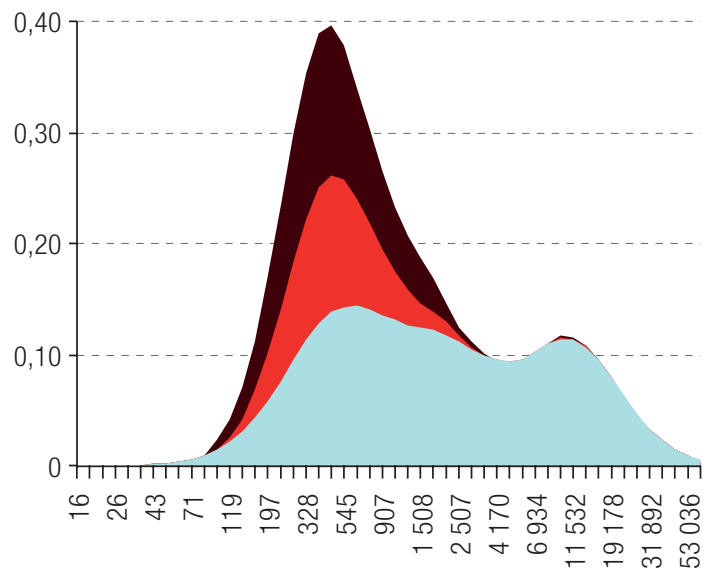

D. 2003

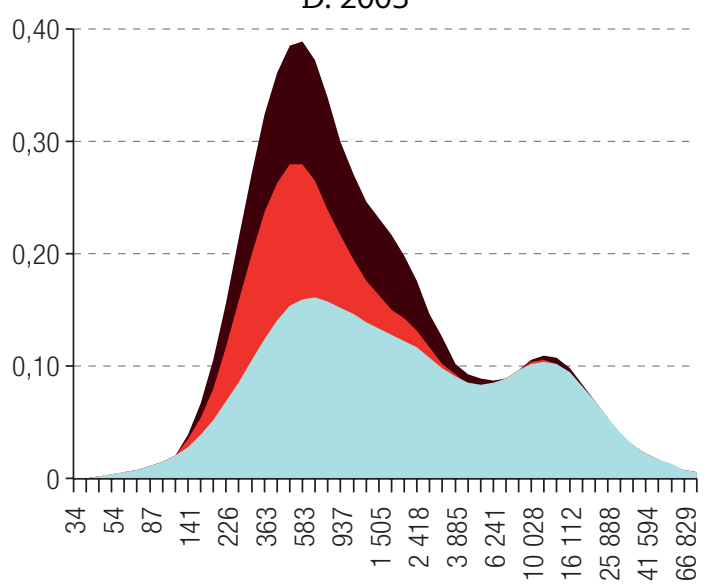

E. 2008

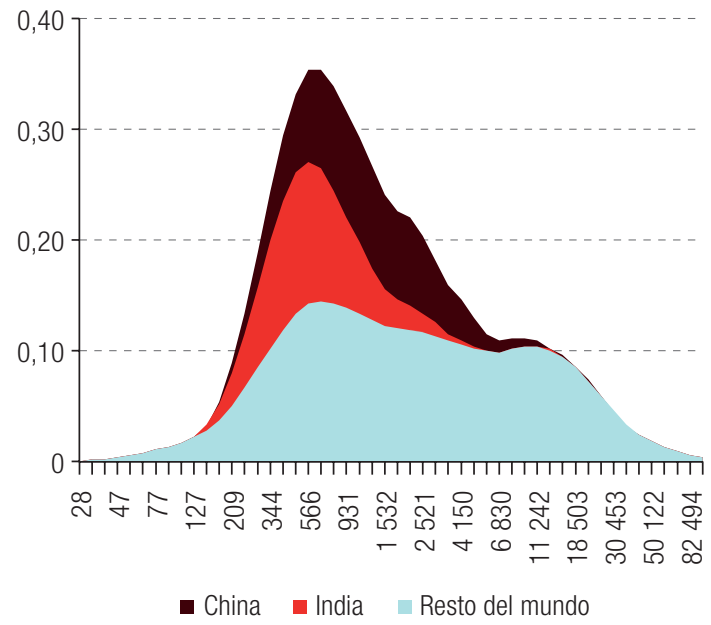

Fuente: C. Lakner y B. Milanovic, "Global income distribution: from the fall of the Berlin Wall to the Great Recession", World Bank Economic Review, vol. 30, № 2, Washington, D.C., Banco Mundial, 2016.

a En escala logarítmica.

b Paridad del poder adquisitivo. 
En suma, los estudios reseñados muestran que, en todos los momentos de tiempo analizados, la desigualdad global es muy alta, similar o superior a la de los países más desiguales del mundo. Entre la década de 1980 y la de 2000, los principales indicadores permanecen estables o presentan, en el mejor de los casos, una leve disminución en los años más recientes. La desigualdad entre los países explica la mayor parte de la desigualdad global y ha caído de forma moderada, mientras que la desigualdad dentro de los países ha aumentado mucho. Estos movimientos se explican principalmente por la evolución de China y la India, cuyo crecimiento económico en el período se dio en el marco de un fuerte crecimiento de la desigualdad interna, pero de un acercamiento al ingreso de los países de ingresos medios.

\section{Desigualdad en países desarrollados y en desarrollo}

La consideración de la desigualdad a nivel de los países es una tarea compleja, ya que el contexto y la evolución difieren. En la literatura se suelen considerar de manera separada los países desarrollados y los que están en desarrollo, ya que los factores determinantes de la desigualdad y su evolución parecen diferir entre ambos grupos.

En los estudios recientes que incluyen información sobre desigualdad en los países desarrollados, se detecta una gran variabilidad en el valor de los indicadores, en un rango que oscila desde un índice de Gini de 0,25 en Dinamarca, Islandia, Noruega y Eslovenia, hasta 0,41 en Turquía y 0,39 en los Estados Unidos, según la información de la Organización de Cooperación y Desarrollo Económicos (OCDE) (véase el gráfico 3). Los países nórdicos (Suecia, Noruega, Dinamarca y Finlandia) se encuentran entre los de menor nivel de desigualdad, junto con los del Benelux (Bélgica, Holanda y Luxemburgo) y algunos países del este de Europa. En el extremo opuesto se ubican Turquía, los Estados Unidos, Israel y Rusia.

Gráfico 3

Países desarrollados: índice de Gini del ingreso equivalente disponible del hogar, alrededor de 2011

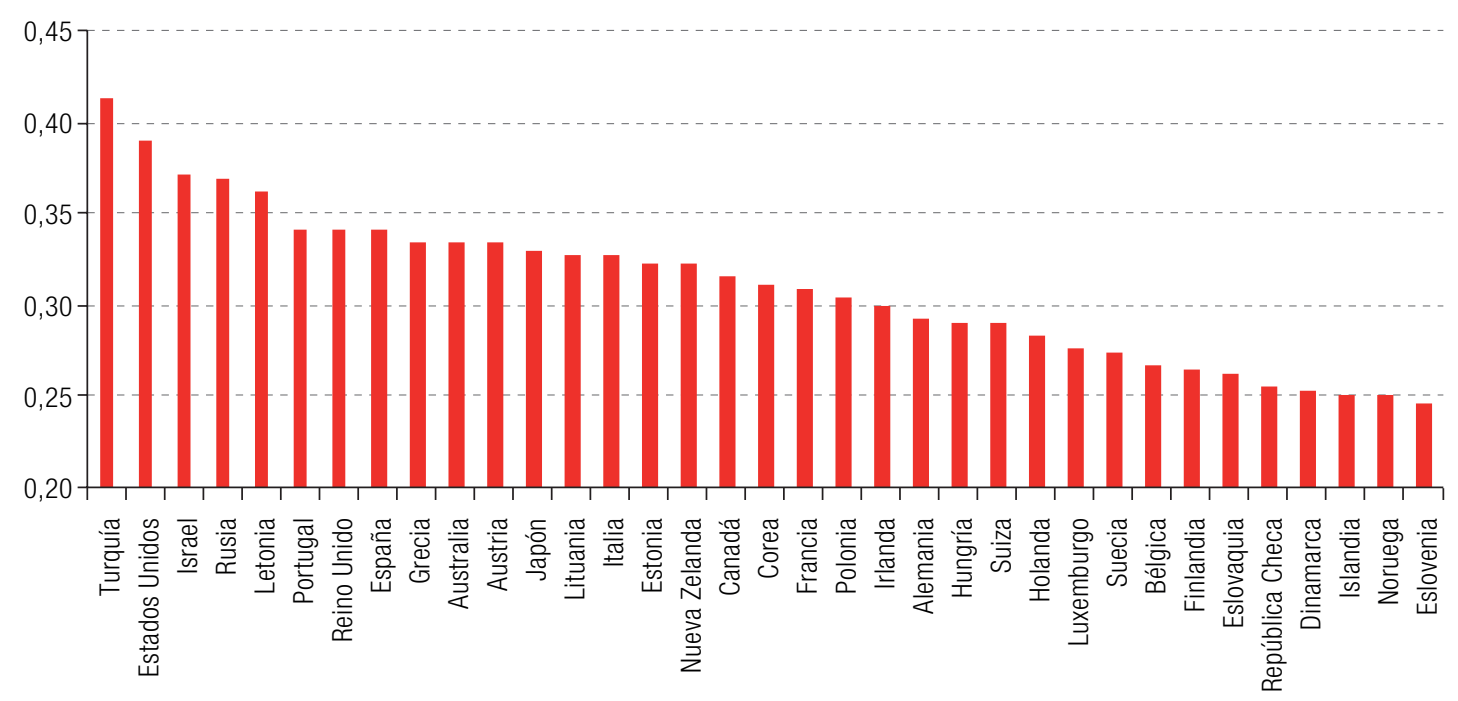

Fuente: Organización de Cooperación y Desarrollo Económicos (OCDE), Base de Datos de Distribución de Ingresos. 
Al considerar la evolución entre 1975 y 2010, se observa que el nivel de desigualdad aumentó en prácticamente todos los países desarrollados de los que se cuenta con información (véase el gráfico 4). Algunos países presentan un fuerte crecimiento de la desigualdad en los ochenta (los Estados Unidos, el Reino Unido y Holanda) y otros en los noventa (Canadá, los países nórdicos y Alemania). Aun en el caso de Francia, donde se logra una importante caída del índice de Gini, en la década de 2000 se presenta un crecimiento del indicador (Morelli, Smeeding y Thompson, 2015). Debido a estos movimientos, en comparación con la década de 1980, la desigualdad entre los países de altos ingresos es menos dispersa. Sin embargo, el ordenamiento de los países en función de su desigualdad permanece básicamente incambiado durante el período.

\section{Gráfico 4}

Países de altos ingresos: evolución del índice de Gini del ingreso disponible del hogar, 1975-2010
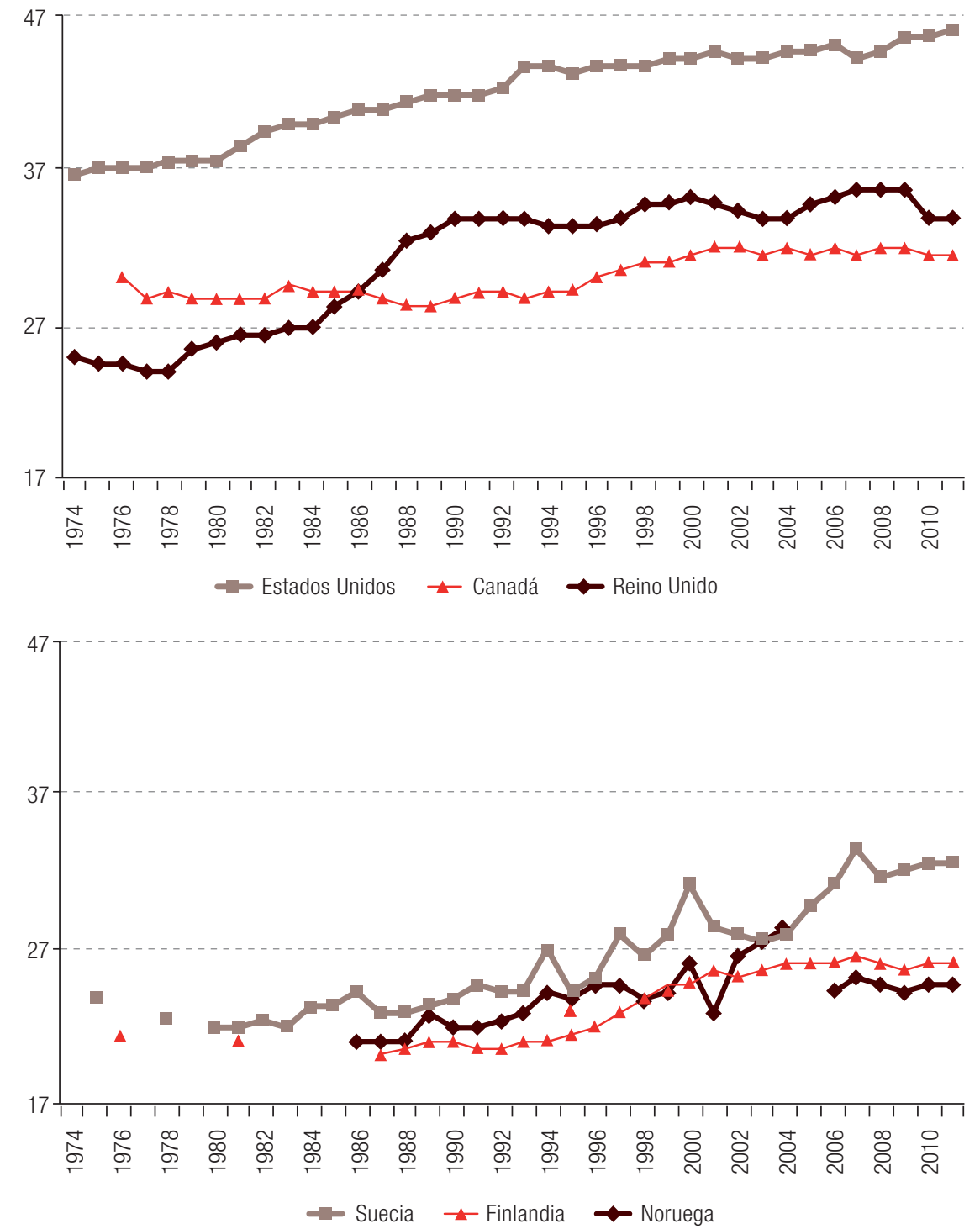
Gráfico 4 (conclusión)

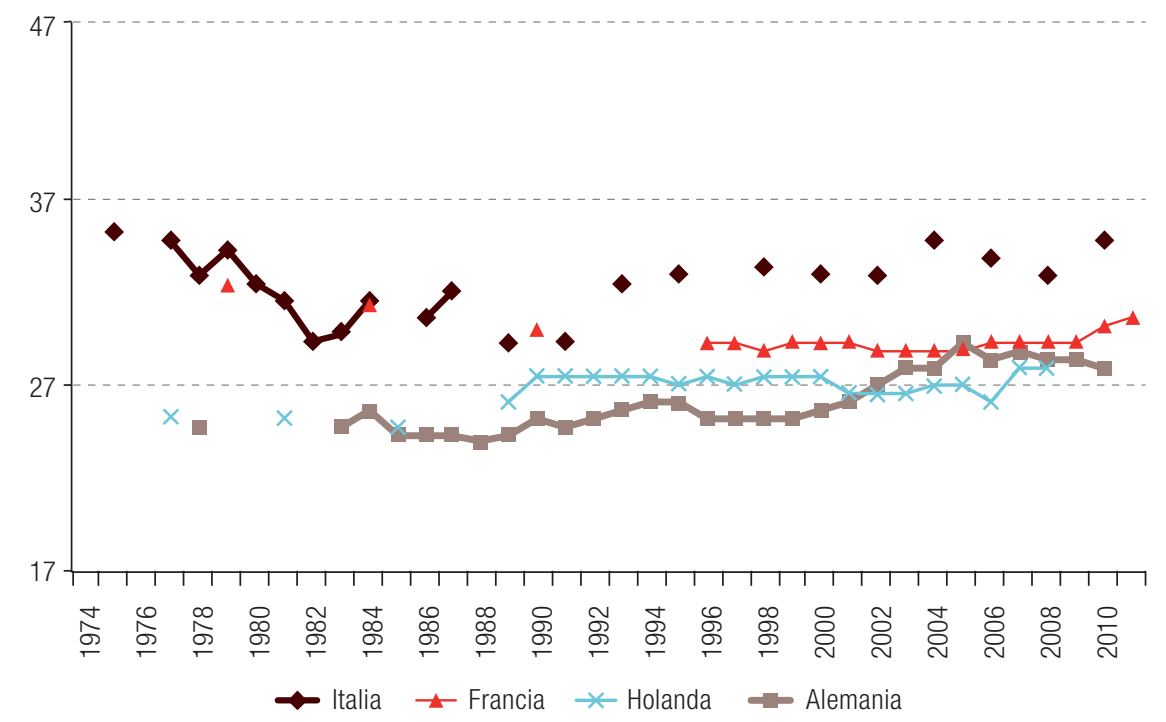

Fuente: Elaboración propia, sobre la base de A. B. Atkinson y S. Morelli, "Chartbook of economic inequality", ECINEQ Working Paper Series, № 2014-324, Sociedad para el Estudio de la Desigualdad Económica (ECINEQ), 2014.

Aunque son evidentes las bondades de las encuestas de hogares en cuanto a que proveen información actualizada y comparable que permite construir indicadores de desigualdad en los distintos países del mundo, dichas encuestas presentan importantes limitaciones en lo que respecta a captar los ingresos altos (Atkinson, Piketty y Sáez, 2011), tanto en los países desarrollados como en los que están en desarrollo. En el caso de los países desarrollados, Morelli, Smeeding y Thompson (2015) muestran cómo, más allá de los problemas metodológicos que supone comparar datos provenientes de registros impositivos, el ranking de países de acuerdo con sus niveles de desigualdad no sufre variaciones relevantes cuando se considera como indicador de desigualdad la apropiación del 1\% superior $^{6}$. Dichos autores también subrayan la tendencia creciente de este indicador en los países desarrollados, así como el hecho de que la crisis financiera de 2008 no ha implicado una ruptura estructural en esa tendencia. En relación con los países de habla inglesa, Piketty y Sáez (2013) encuentran que, si se consideraran los ingresos de los más ricos de manera adecuada, el incremento de la desigualdad sería aún más pronunciado.

Las razones de este incremento en el nivel de desigualdad en los países desarrollados siguen siendo objeto de debate: se han señalado diversos factores como explicativos de esta tendencia. Por un lado, el proceso de innovación tecnológica podría haber incrementado la demanda de trabajadores calificados y con ello el diferencial salarial a su favor. La liberalización comercial y financiera, además de la globalización, podrían haber tenido un efecto similar que habría impulsado la valorización del trabajo calificado en las economías desarrolladas y el incremento de la desigualdad. En la práctica es muy difícil separar ambos efectos - globalización y liberalización comercial-, ya que los avances tecnológicos, por ejemplo, permiten fragmentar las actividades productivas y producir en el extranjero, lo que puede interpretarse como un efecto de la especialización comercial (OCDE, 2011). Más recientemente, y sobre todo a partir de la crisis financiera mundial de 2008, se ha enfatizado en el creciente peso del sector financiero en las economías. En esta línea va el difundido argumento de Piketty (2014) de que la tasa de retorno del capital ha sido superior a la de crecimiento económico en

6 Ruiz y Woloszko (2016) aplican un ajuste estadístico a los datos de las encuestas de hogares de países desarrollados y encuentran resultados similares. 
el largo plazo, y este retorno se ha concentrado en muy pocas manos, lo que ha incentivado un gran crecimiento de la desigualdad económica.

En el caso de los países en desarrollo, la dispersión de los niveles de desigualdad es mayor que en los países desarrollados, con un diferencial de casi 40 puntos entre ellos: desde un índice de Gini de 25,6 en Ucrania, hasta uno de 63,1 en Sudáfrica (Alvaredo y Gasparini, 2015). En el gráfico 5 se presentan los índices de Gini de 122 países en desarrollo agrupados según la región a la que pertenecen ${ }^{7}$. África Subsahariana es la región que contiene los países con los mayores niveles de desigualdad, pero también es la que tiene más dispersión. Su media (no ponderada) es la mayor del mundo, pero la mediana de América Latina es superior. Más aún, casi todos los países con niveles muy altos de desigualdad (Gini superior a 50) se ubican en África Subsahariana, pero en esa región hay una participación similar de países con niveles medios o altos de desigualdad. Sin embargo, prácticamente todos los países de América Latina se ubican en niveles altos de desigualdad. Solo en la región de Europa Oriental y Asia Central se encuentran países con desigualdad baja (menos de 30 puntos). En las otras tres regiones, la mayoría de los países se ubican en el nivel medio de desigualdad.

\section{Gráfico 5}

Países en desarrollo: índice de Gini del consumo per cápita del hogar, alrededor de 2010

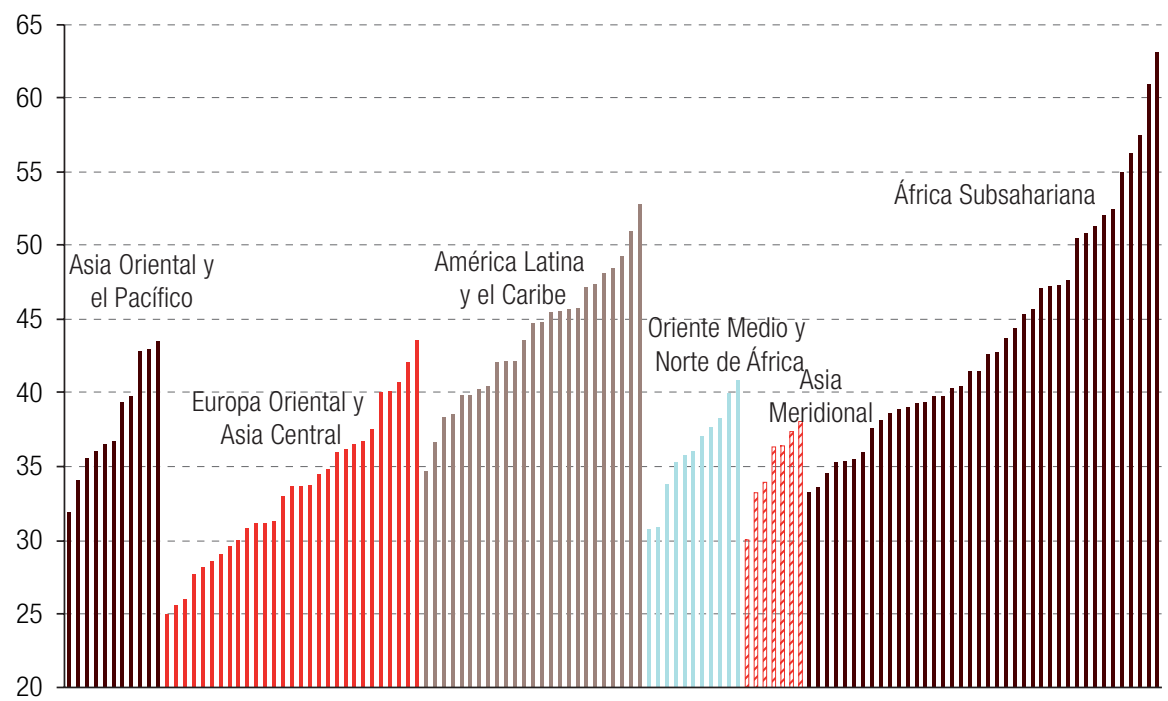

Fuente: F. Alvaredo y L. Gasparini, "Recent trends in inequality and poverty in developing countries", Handbook of Income Distribution, A. Atkinson y F. Bourguignon (eds.), vol. 2, Amsterdam, Elsevier, 2015.

Las variaciones entre los países son mucho más fuertes que los cambios que estos sufren en el tiempo. Alvaredo y Gasparini (2015) analizan un panel de países en desarrollo en el período de 1981 a 2010 y observan que el $88,5 \%$ de la varianza del panel se debe a diferencias entre los países. Asimismo, los autores señalan que, aun cuando el mundo en desarrollo atravesó importantes cambios políticos, económicos y sociales en las últimas cuatro décadas, el ordenamiento de los países prácticamente no se modificó. Este hecho sugiere que hay ciertos factores subyacentes que afectan mucho el nivel de desigualdad de un país y que no se han modificado en el tiempo. En el gráfico 6 se muestran los movimientos del índice de Gini promedio por región entre 1990 y 2010, calculado sobre la base del consumo per cápita que se presenta en el mencionado artículo.

7 Estas cifras surgen de PovcalNet, que presenta la distribución del consumo per cápita, salvo para América Latina y algunos países del Caribe, en relación con los cuales se presenta la distribución del ingreso per cápita. Para que los datos sean comparables, Alvaredo y Gasparini (2015) ajustan los registros de esta región sobre la base del índice de Gini del consumo o el ingreso tomado de siete países de los que se cuenta con información al respecto. En esos siete países, el promedio del índice de Gini del consumo o el ingreso es de 0,861. 


\section{Gráfico 6}

Países en desarrollo (seis regiones): índice de Gini calculado sobre la base del consumo per cápita, 1990-2010ª

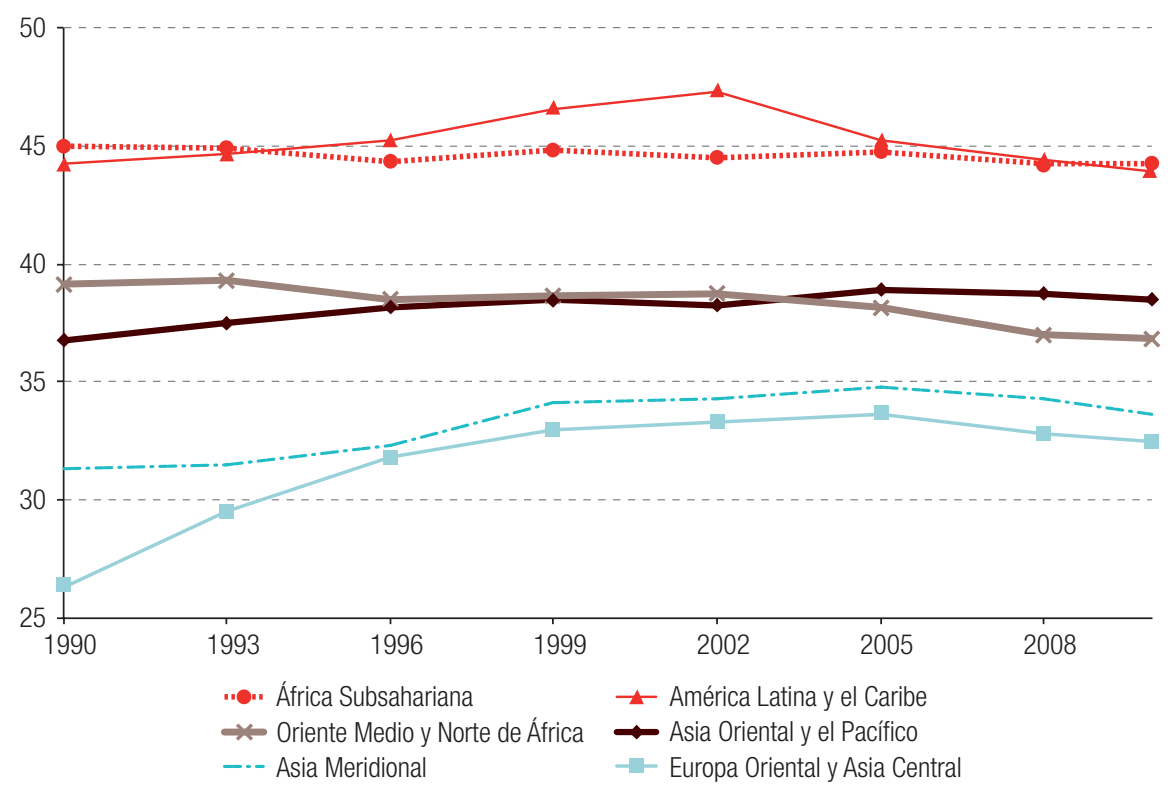

Fuente: F. Alvaredo y L. Gasparini, "Recent trends in inequality and poverty in developing countries", Handbook of Income Distribution, A. Atkinson y F. Bourguignon (eds.), vol. 2, Amsterdam, Elsevier, 2015.

a Promedio no ponderado por regiones.

Mientras que en América Latina se observa un incremento del índice de Gini en la década de 1990 y una caída mayor en la de 2000, el índice de África Subsahariana se mantiene prácticamente incambiado. Por otro lado, en los países de Asia y Europa Oriental se evidencia un fuerte aumento de la desigualdad. Dentro de los países de Asia, el aumento más significativo en la desigualdad corresponde a China, cuyo movimiento de ingresos fue de tal relevancia que impactó en la distribución global, como se analizó en la sección anterior. Este fenómeno se analiza en la sección siguiente, mientras que la evolución de la desigualdad en América Latina se analiza con mayor profundidad en la sección V.

\section{Análisis más profundo de algunas realidades: la desigualdad en China}

Los cambios en el ingreso de los hogares de China han sido de tal magnitud que han implicado un corrimiento de la distribución global del ingreso hacia la derecha, así como una modificación de su forma, como se analizó en la sección I. La expansión de la producción china y el aumento de la cantidad de puestos de trabajo condujeron a un aumento significativo de la remuneración de los trabajadores y el ingreso de los hogares. Eso significó, por un lado, una reducción muy relevante de los niveles de pobreza: de acuerdo a las estimaciones del Banco Mundial, la cantidad de personas con ingresos per cápita inferiores a 2 dólares por día (a precios de 2005, considerando la paridad del poder adquisitivo) pasó de representar el 84\% en 1987 a ubicarse algo por debajo del 19\% en 2011. Si se considera un umbral de pobreza de 1,25 dólares, la incidencia de esta cayó del $54 \%$ al $6 \%$ en el mismo período. 
Por otro lado, se produjo un incremento sostenido del nivel de desigualdad: las ganancias producidas por el significativo crecimiento chino no se repartieron de igual manera entre los distintos hogares, grupos sociales o regiones del país. El último guarismo disponible del índice de Gini (2012) asciende a 54, lo que implica un crecimiento de 25 puntos, si se lo compara con el dato correspondiente a 1982, y de casi 15 puntos en relación con los valores de 2000 (véase el gráfico 7). Es decir que, junto con el notable crecimiento de la economía y la caída de la pobreza, el nivel de desigualdad se ha disparado.

Gráfico 7

China: crecimiento económico y desigualdad, 1981-2014

(En porcentajes e indices de Gini)

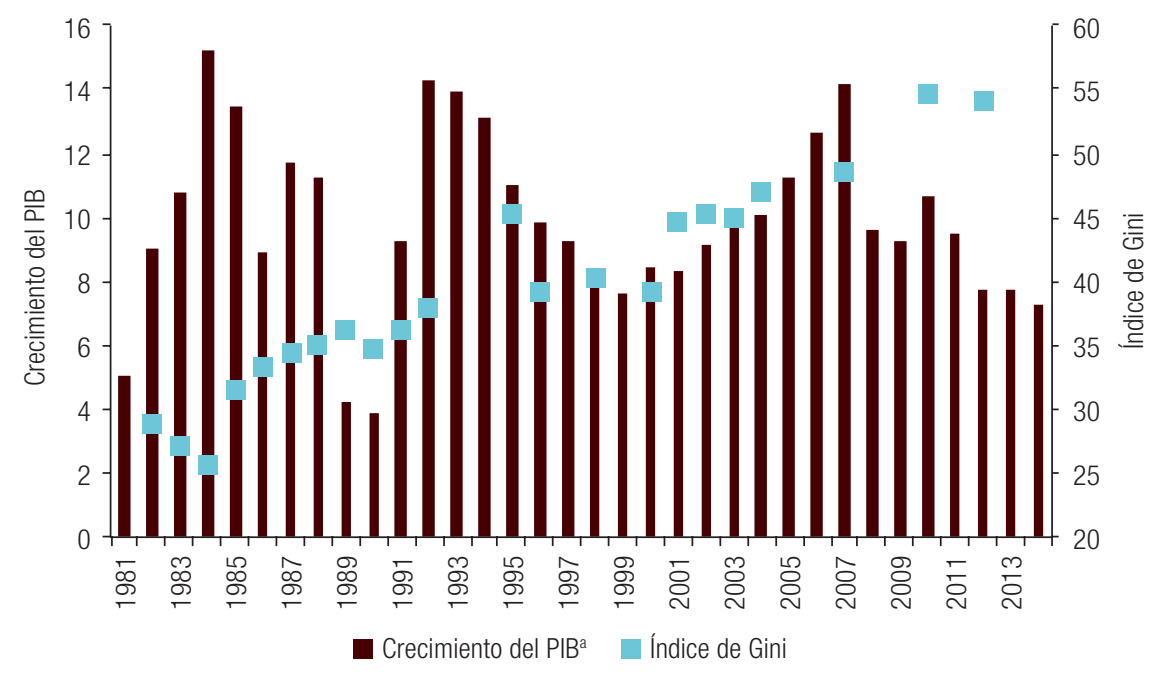

Fuente: Fondo Monetario Internacional (FMI), World Economic Outlook Database e Instituto Mundial de Investigaciones de Economía del Desarrollo (UNU-WIDER), World Income Inequality Database.

a Producto interno bruto.

En numerosos estudios se ha subrayado el vertiginoso incremento de la desigualdad de los ingresos desde la reforma económica de 1978 (Meng, Shen y Xue, 2013; Xie y Zhou, 2014). Esta reforma incentivó la rápida urbanización e industrialización de determinadas "zonas económicas especiales", donde se concentró el motor del crecimiento de la economía en los últimos 25 años. Hacia esas zonas llegaron los capitales extranjeros, lo que dio lugar a emprendimientos industriales y amplió en gran medida la demanda laboral. Esto se acompañó con programas de subsidio a la vivienda en zonas urbanas, en el marco de un fuerte proceso de migración hacia ellas desde las zonas rurales. En función de todo este proceso, hoy en día existe una diferencia significativa entre los salarios que se perciben en la zona costera urbana y los que se perciben en la zona rural continental (Tao Yang y Zhou, 1999; Sicular y otros, 2007). Dado que los condados son los encargados de cobrar buena parte de los ingresos fiscales y de prestar servicios como la educación, la salud e incluso las pensiones, se producen grandes diferencias en la calidad de los servicios públicos entre las zonas que tienen distintos niveles de ingresos (Dollar, 2007).

Además de la desigualdad regional, las primas por educación han aumentado considerablemente y en la actualidad constituyen un fuerte elemento diferenciador entre los salarios de los trabajadores urbanos de China (Xie y Zhou, 2014). Entre 1988 y 1995, las primas por educación casi se duplicaron (Hauser y Xie, 2005) y la tendencia creciente continuó en los años posteriores (Jansen y Wu, 2012). Anteriormente, los niveles salariales eran muy similares entre las distintas profesiones y capacidades técnicas. El proceso de reformas, con el mayor peso del mercado y la retracción de la actividad y el empleo en el sector público en los últimos años, ha influido en el incremento del diferencial salarial 
por nivel educativo. A partir de 1999, el Gobierno chino instauró una política de expansión educativa a nivel terciario gracias a la cual la proporción de población urbana con título universitario pasó de ser inferior al 10\% en 2003 a superar el 20\% en 2010. Este cambio, junto con las demás variantes en el nivel educativo de la fuerza laboral china entre 1996 y 2010, parece haber contribuido al aumento de la desigualdad (Zhou, 2014). El hecho de que la población china haya visto incrementarse su nivel absoluto de ingresos junto con un rápido incremento del nivel de desigualdad coincide con la caída del nivel de felicidad o satisfacción con la vida entre 1990 y finales de 2000 que se detectó en diversos trabajos (Bartolini y Sarracino, 2014; Brockmann y otros, 2009). Este hecho se ha asociado a parte de la población china que, a pesar de haber mejorado su situación en términos absolutos, está en una posición desventajosa en términos relativos y se siente frustrada en relación con sus expectativas.

\section{Análisis más profundo de algunas realidades: la desigualdad en América Latina}

En esta sección se analiza en detalle la evolución de la desigualdad en América Latina en el último decenio, entre 2002 y 2014. Del mismo modo en que se analizó la desigualdad a nivel mundial, se comienza por un análisis basado en la metodología de la desigualdad global, considerando a la región como un todo, para luego poner el foco en las realidades nacionales.

\section{Desigualdad regional}

La aplicación de una metodología similar a la de los estudios globales de desigualdad, pero considerando solamente los países de América Latina, permite analizar qué tan desiguales son los ingresos de los habitantes de la región considerada en su conjunto y cómo ha evolucionado esa desigualdad. Dado que este cálculo involucra una menor cantidad de países, es posible combinar los datos individuales de todas las encuestas de hogares de los países de la región, en lugar de combinar ventiles como se hace en los estudios de desigualdad global a nivel del mundo. Se obtiene así un vector de ingresos regional y se analiza su distribución y las modificaciones recientes, para averiguar si los cambios distributivos en el interior de los países de la región durante el último decenio han estado acompañados de mejoras en la distribución del ingreso entre los latinoamericanos o si han implicado un incremento de las brechas. A continuación, se presentan los resultados de un ejercicio de este tipo en el que se actualiza el análisis de Amarante, Galván y Mancero (2016), considerando 16 países de la región en tres momentos de tiempo: alrededor de 2002, 2009 y 2014². Además, se presentan algunos ejercicios de simulación?

Se utilizan dos vectores alternativos para obtener ingresos comparables entre los países. En primer lugar, se usa el ingreso per cápita de los hogares ajustado por PPA (Banco Mundial, 2015) $)^{10,11}$.

8 Un análisis similar puede encontrarse en Cord y otros (2016).

9 En el cuadro A1.1 del anexo se presenta un detalle de las encuestas y los años utilizados.

${ }^{10}$ Los ingresos se llevaron al año 2011 mediante la variación observada en el índice de precios al consumidor (IPC) general de cada país, de manera de aplicar los factores de PPA estimados para ese año. En el caso de la Argentina, a partir de 2007 se utilizó como deflactor el promedio simple de los índices de precios de cinco provincias. Debido a que existe cierta discusión en torno a la fiabilidad de las estimaciones realizadas según la PPA de 2011, se realizan todas las estimaciones utilizando los factores de conversión PPA de 2005. Los resultados son muy similares y es posible solicitárselos a las autoras.

${ }^{11}$ En relación con ambos vectores de ingreso (ajustado por PPA y deflactado por líneas de pobreza), se utiliza el ingreso de los hogares corregido por no respuesta a las encuestas y ajustado a las cifras de las cuentas nacionales. Este es el ingreso que la CEPAL aplicaba para calcular la pobreza hasta 2016 (véase CEPAL, 2014b). A partir del Panorama Social de América Latina 2016 (CEPAL, 2016), se presenta una nueva serie de ingresos de los hogares en la que se revisan desde el punto de vista conceptual y operativo las distintas partidas incluidas y la imputación de la no respuesta. Asimismo, se deja de ajustar las cifras a las cuentas nacionales. 
Como una forma alternativa de igualar el poder adquisitivo de los hogares y analizar la robustez de los resultados, se consideran como deflactores de los precios las líneas de pobreza que la Comisión Económica para América Latina (CEPAL) calcula para estimar la pobreza a nivel regional. Dichas líneas representan el costo de adquirir una canasta básica de alimentos y de bienes que satisfagan otras necesidades básicas y puede asumirse que, por tanto, reflejan las diferencias en el costo de alcanzar un nivel de bienestar similar entre los países.

La simple visualización de la distribución global del ingreso ajustado por PPA de América Latina muestra su importante desplazamiento hacia la derecha entre 2002 y 2009, lo que refleja el crecimiento del ingreso de los hogares (véase el gráfico 8). Dicho movimiento se repite, en menor medida, en 2014. También resulta visualmente evidente la menor dispersión de la distribución cuando se compara una punta del período con la otra.

Gráfico 8

América Latina: distribución del ingreso, 2002, 2009 y 2014a

(En densidad del ingreso logarítmico y en dólares PPA ${ }^{\mathrm{b}}$ de 2011)

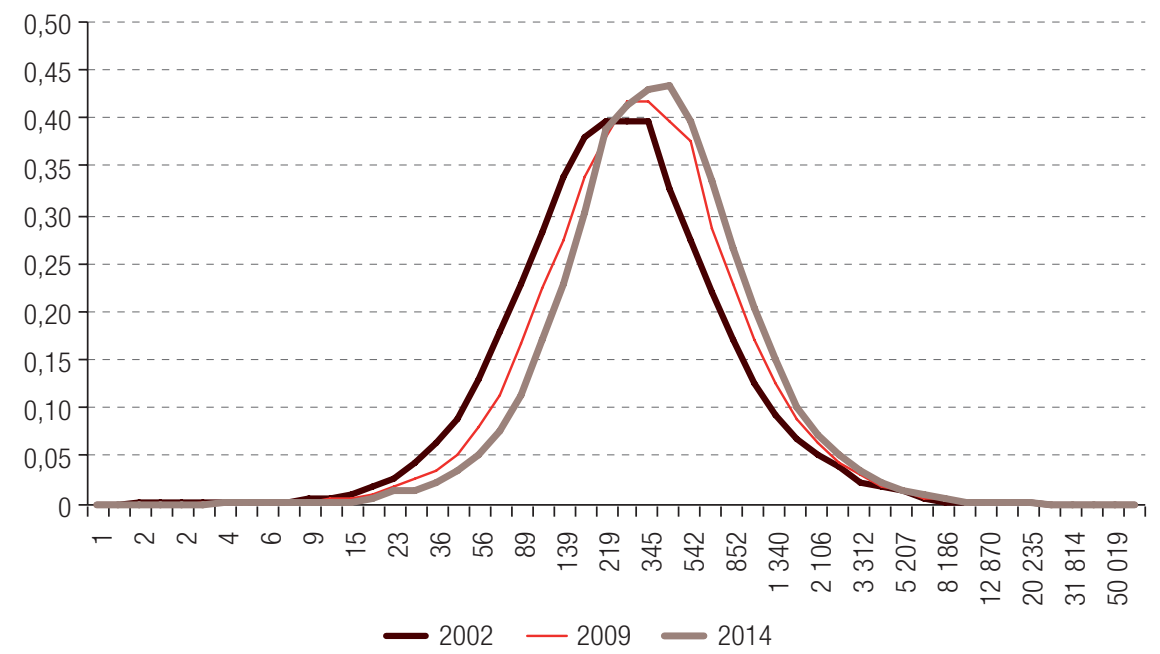

Fuente: Elaboración propia, sobre la base de encuestas de hogares.

a En escala logarítmica y ponderado por la población.

b Paridad del poder adquisitivo.

En efecto, entre 2002 y 2014, el ingreso per cápita promedio de los habitantes de América Latina, expresado en paridad del poder adquisitivo, creció el 30,5\%. Si se lo expresa en relación con la línea de pobreza, la variación en el período es del 39,7\%. Entre 2002 y 2014, la variación del ingreso fue positiva en todos los percentiles. Sin embargo, este crecimiento no es uniforme en toda la distribución: los percentiles de ingresos más bajos presentaron un crecimiento mayor, como se evidencia al analizar los cambios por decil y percentil (véase el gráfico 9). Tanto en términos del ingreso ajustado por PPA, como del relativo a la línea de pobreza, se aprecia que la variación decrece con el nivel de ingresos. En palabras de Ravallion y Chen (2003), la curva de incidencia del crecimiento refleja que este ha sido favorable a los pobres. Esta evolución es más marcada en el caso del ingreso ajustado por PPA, que presenta un crecimiento más importante que el ingreso ajustado por línea de pobreza en relación con los hogares de la primera mitad de la distribución del ingreso. El mayor crecimiento del ingreso de los individuos ubicados en la parte baja de la distribución regional es por tanto un primer indicio de la caída de la desigualdad global en la región. 


\section{Gráfico 9}

América Latina: variación del ingreso real de la población, 2002-2014a

(En porcentajes)

A. Por percentiles de la distribución regional

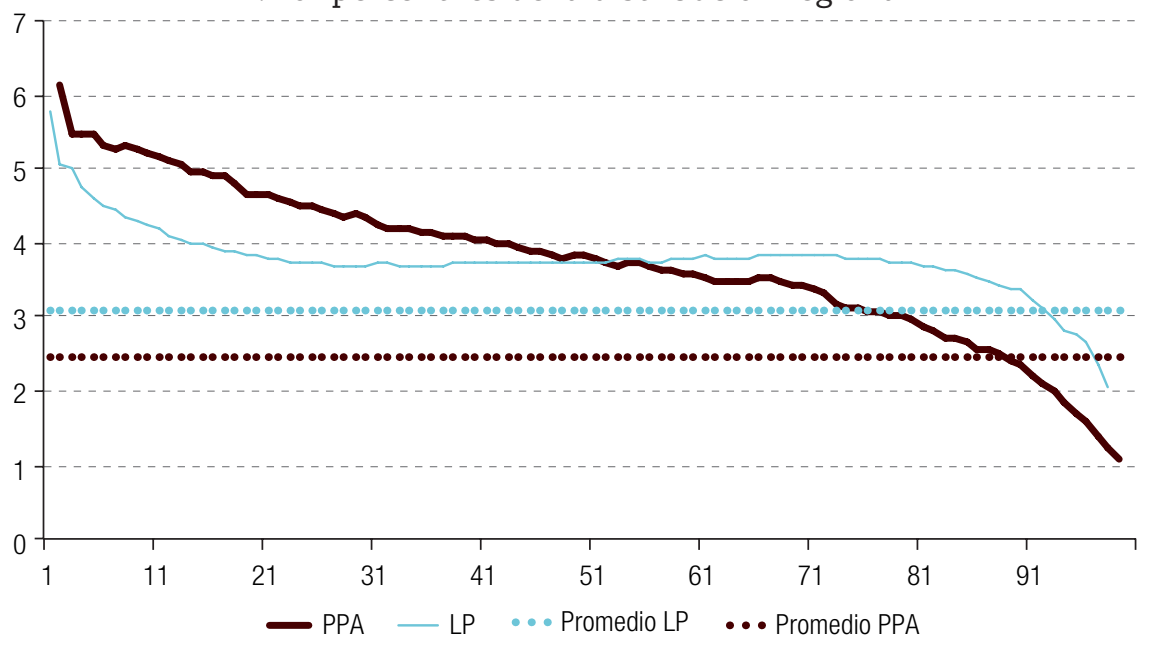

B. Por deciles de la distribución regional

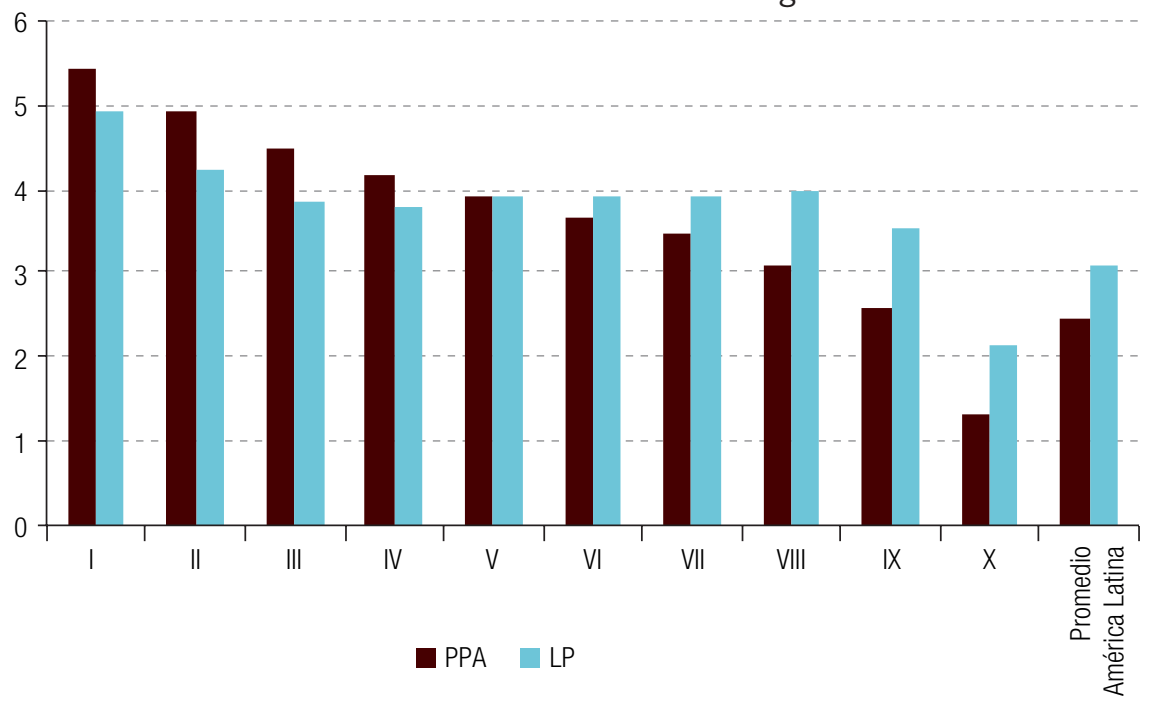

Fuente: Elaboración propia, sobre la base de encuestas de hogares.

Nota: PPA significa paridad del poder adquisitivo y LP significa línea de pobreza.

a Variación anual equivalente.

A diferencia de lo que ocurre a nivel global, los indicadores de desigualdad de América Latina no difieren de forma significativa de las observaciones subregionales o nacionales, lo que sugiere cierta homogeneidad en la región, a pesar de que el nivel del indicador es alto en comparación con otras regiones. Esto indica que las diferencias entre los habitantes de América Latina son relativamente similares a las que se encuentran entre los habitantes de cada país. Respecto a su evolución, los tres indicadores considerados (Gini, Theil y ratio 90/10) presentan una mejora entre 2002 y 2014, tanto cuando se los mide en paridad del poder adquisitivo como respecto a la línea de pobreza (véase el cuadro 2). Sin embargo, en la mayoría de los indicadores, la mayor parte de la mejora se observa entre 
2002 y 2009, mientras que en los últimos años el ritmo de reducción de la desigualdad se desacelera sustancialmente, en especial cuando se analizan los ingresos respecto a la línea de pobreza.

\section{Cuadro 2}

América Latina: índices de desigualdad global, 2002, 2009 y 2014

(En puntos de los indicadores y en porcentajes)

\begin{tabular}{|c|c|c|c|c|c|c|}
\hline & 2002 & 2009 & 2014 & $\begin{array}{l}\text { Variación anual } \\
\text { equivalente } \\
\text { 2002-2014 }\end{array}$ & $\begin{array}{l}\text { Variación anual } \\
\text { equivalente } \\
\text { 2002-2009 }\end{array}$ & $\begin{array}{c}\text { Variación anual } \\
\text { equivalente } \\
2009-2014\end{array}$ \\
\hline \multicolumn{7}{|l|}{ Ingreso PPA } \\
\hline Índice de Gini & 0,588 & 0,553 & 0,532 & $-0,8$ & $-0,9$ & $-0,8$ \\
\hline Índice de Theil & 0,767 & 0,653 & 0,595 & $-2,1$ & $-2,3$ & $-1,8$ \\
\hline Ratio 90/10 & 14,5 & 12,6 & 10,9 & $-2,4$ & $-2,0$ & $-2,9$ \\
\hline \multicolumn{7}{|l|}{ Ingreso LPb } \\
\hline Índice de Gini & 0,580 & 0,552 & 0,551 & $-0,4$ & $-0,7$ & 0,0 \\
\hline Índice de Theil & 0,772 & 0,664 & 0,648 & $-1,4$ & $-2,1$ & $-0,5$ \\
\hline Ratio 90/10 & 12,3 & 11,4 & 11,3 & $-0,7$ & $-1,1$ & $-0,1$ \\
\hline
\end{tabular}

Fuente: Elaboración propia, sobre la base de encuestas de hogares.

a Paridad del poder adquisitivo.

b Línea de pobreza.

Si la desigualdad del ingreso entre los habitantes de la región se descompone distinguiendo la desigualdad entre los países y la que hay en el interior de estos (sobre la base del índice de Theil), se observa que la mayor parte de la desigualdad regional corresponde a la que hay en el interior de los países (véase el cuadro 3). Alrededor del 90\% de la desigualdad global en la región obedece a diferencias dentro de los países. Este resultado difiere del que surge de las descomposiciones mundiales que se analizaron antes, que indican que entre el $60 \%$ y el $85 \%$ de la desigualdad global a nivel del mundo (dependiendo de las medidas y los años considerados) deriva de diferencias entre el ingreso medio de los países, y que esta viene cayendo. Al restringir el análisis a América Latina, se detecta una mayor homogeneidad entre los países, lo que es de esperar al reducir la cantidad de países que se incluyen en el cálculo. A su vez, la desigualdad en el interior de los países es la que determina la desigualdad regional casi en su totalidad. Estos resultados indican que la dinámica interna de los países, vinculada con sus realidades sociales, institucionales y políticas, resulta más relevante para la consideración de la desigualdad regional que la dinámica entre los países (como la vinculada a la migración o el comercio). De todos modos, los resultados son similares a los que encontraron Amarante, Galván y Mancero (2016) para la región. Por otro lado, es válido recordar que la contribución de cada país a la desigualdad global depende principalmente de su participación en el ingreso total de los hogares de la región, y por lo tanto se destaca la importancia del Brasil y México, cuyo peso en la descomposición es muy elevado (véase el cuadro A1.2 del anexo).

Además, la reducción de la desigualdad global de la región en el período se explica fundamentalmente por la caída de la desigualdad en el interior de los países. Una vez más, en este resultado tienen mucha importancia los procesos de mejora distributiva que han tenido lugar en el Brasil y México. La importancia del componente de desigualdad entre los países (que refleja las diferencias entre el ingreso medio por país) se ha incrementado. La desigualdad entre los países explica una parte menor, aunque creciente, de la desigualdad global en la región. Estos resultados indican que las condiciones de vida de los habitantes de América Latina son más igualitarias en términos relativos hoy que hace un decenio, aunque las diferencias entre el ingreso promedio de los países son mayores. Estos resultados sobre la caída de la desigualdad global en la región, así como la prevalencia absoluta de la desigualdad intrapaíses y su efecto desconcentrador, son similares, aunque más marcados, a los que informan Gasparini y Gluzmann (2012) en relación con el período de 1992 a 2006 y a los que señalan Amarante, Galván y Mancero (2016). 


\section{Cuadro 3}

América Latina: descomposición del índice de Theil por país, 2002, 2009 y 2014 (En puntos del índice de Theil y en porcentajes)

\begin{tabular}{|c|c|c|c|c|c|c|}
\hline & \multicolumn{3}{|c|}{ Descomposición de Theil } & \multicolumn{3}{|c|}{ Importancia de los componentes } \\
\hline & 2002 & 2009 & 2014 & 2002 & 2009 & 2014 \\
\hline \multicolumn{7}{|l|}{ Ingreso PPA } \\
\hline Intrapaíses & 73,7 & 61,0 & 55,1 & 96 & 93 & 93 \\
\hline Entre países & 3,0 & 4,4 & 4,4 & 4 & 7 & 7 \\
\hline Theil & 76,7 & 65,3 & 59,5 & 100 & 100 & 100 \\
\hline \multicolumn{7}{|l|}{ Ingreso LPb } \\
\hline Intrapaíses & 73,1 & 66,4 & 54,9 & 95 & 92 & 85 \\
\hline Entre países & 4,1 & 5,5 & 9,9 & 5 & 8 & 15 \\
\hline Theil & 77,2 & 60,9 & 64,8 & 100 & 100 & 100 \\
\hline
\end{tabular}

Fuente: Elaboración propia, sobre la base de encuestas de hogares.

a Paridad del poder adquisitivo.

b Línea de pobreza.

Se realizan dos ejercicios de simulación (véase el cuadro 4). El primero consiste en calcular cómo sería la distribución del ingreso en América Latina en 2014 si solo hubiera cambiado la estructura de este, pero no hubiera aumentado el ingreso medio respecto a 2002 (efecto distribución). El segundo consiste en calcular cómo sería la distribución del ingreso en América Latina en 2014 si solo hubiera cambiado el ingreso medio de los países, pero no su estructura respecto a 2002 (efecto crecimiento). Si el ingreso no hubiera aumentado entre 2002 y 2014, pero sí hubiera cambiado su estructura, el índice de Gini presentaría una caída aún mayor de la observada (sería 0,524 en lugar de 0,532 en 2014). Sin embargo, si solo hubiera aumentado el ingreso, pero no hubiera cambiado su estructura, la desigualdad habría aumentado y el índice de Gini sería de 0,595 en 2014. Esto indica que los dos movimientos observados en el período operan en sentido contrario en relación con la desigualdad: el aumento del ingreso promedio ha sido desigualador, pero la modificación de la estructura de los ingresos ha compensado con creces ese efecto ${ }^{12}$.

\section{Cuadro 4}

América Latina: simulaciones de la desigualdad de los ingresos per cápita, 2014 (En dólares PPA a de 2011y en puntos de los indicadores)

\begin{tabular}{lcccc}
\hline & 2002 & 2014 & Efecto distribución & Efecto crecimiento \\
\hline Ingreso medio & 477 & 622 & 475 & 623 \\
\hline Índice de Gini & 0,588 & 0,532 & 0,524 & 0,595 \\
\hline Índice de Theil & 0,767 & 0,595 & 0,581 & 0,752 \\
\hline Ratio 90/10 & 14,5 & 10,9 & 10,6 & 14,3 \\
\hline
\end{tabular}

Fuente: Elaboración propia, sobre la base de encuestas de hogares.

a Paridad del poder adquisitivo.

En síntesis, así como se encontraba en Amarante, Galván y Mancero (2016) en relación con el período de 2002 a 2012, los indicadores de desigualdad regional muestran una caída significativa en el período de 2002 a 2014, lo que indica que las diferencias relativas entre toda la población de la región son menores que hace un decenio. La reducción de la desigualdad en el interior de los países es la que explica fundamentalmente la reducción de la desigualdad global de la región y es sobre todo el cambio de la estructura del ingreso (el efecto distribución) el que explica esta caída de la desigualdad regional.

$12 \mathrm{Si}$ las descomposiciones se realizan tomando como base el año final del período en lugar del inicial, los resultados son casi idénticos. 


\section{Desigualdad a nivel nacional}

A partir de 2002, América Latina presenta una caída de la desigualdad de ingresos, medida a través del índice de Gini, en casi todos los países analizados (véase el gráfico 10). Las dos excepciones son Costa Rica y la República Dominicana, que presentan un aumento del índice (en el último caso, solo en 2009) ${ }^{13}$. Los mejores logros relativos entre 2002 y 2014 se presentan en el Estado Plurinacional de Bolivia, la República Bolivariana de Venezuela, la Argentina, el Paraguay y el Uruguay, con una reducción superior al $4 \%$ anual ${ }^{14}$.

Gráfico 10

América Latina (16 países): índice de Gini, 2002, 2009 y 2014

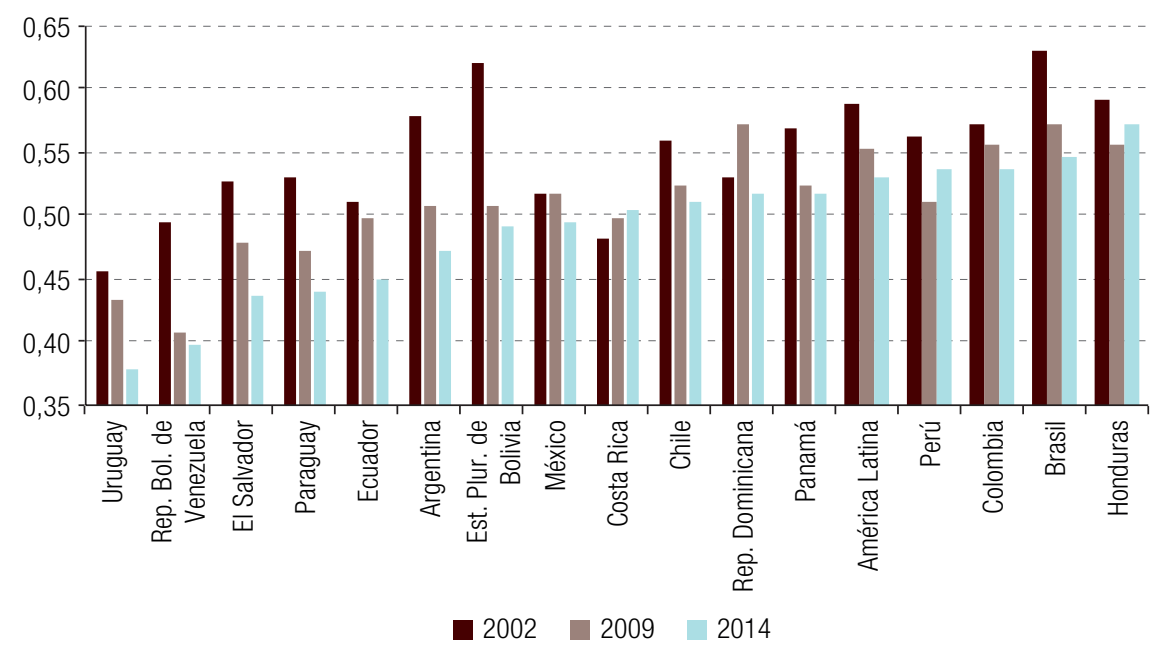

Fuente: Elaboración propia, sobre la base de encuestas de hogares.

La disparidad en cuanto a los logros de los países modifica su ubicación relativa respecto a la desigualdad de los ingresos. Los ejemplos más claros son los de la Argentina y el Estado Plurinacional de Bolivia, que en 2002 se ubicaban entre los cinco países más desiguales de la región (junto con el Brasil, Honduras y Colombia), mientras que en 2014 se ubican en la mitad superior de la tabla, en la posición 6 y 7 , respectivamente.

La desigualdad de ingresos en América Latina mostraba una tendencia creciente desde los ochenta, con una dinámica diferente en cada país, pero con la gran persistencia y el nivel elevado que han caracterizado la historia de la región. La caída que comienza a verificarse a partir de 2002 en la mayoría de los países responde en gran parte a lo sucedido en el mercado de trabajo, donde se redujo de manera considerable la dispersión del ingreso laboral. En un contexto en el que el ingreso promedio varió significativamente, el ingreso de la parte más baja de la distribución — donde se ubican los trabajadores menos calificados - creció más, lo que redujo el diferencial por calificación. Esto podría obedecer a un incremento de la oferta de trabajadores calificados, a un aumento de la demanda de trabajadores menos calificados o a una combinación de ambos. Más allá de los patrones generales, las experiencias nacionales son disímiles y hay diversos factores que, operando con diferente intensidad, pueden haber contribuido a la mencionada reducción. La discusión al respecto es profusa y se puede hallar, por ejemplo, en CEPAL (2014a), Gasparini y otros (2012), y Cornia (2014),

\footnotetext{
${ }^{13}$ En el caso de Costa Rica, cabe resaltar que en 2010 se hacen cambios metodológicos en la encuesta de hogares que generan dudas sobre la comparabilidad de la serie.

${ }^{14}$ La reducción de la desigualdad del ingreso se produce un poco más tarde en el tiempo, a partir de 2007.
} 
entre otros. En términos generales, la estabilidad macroeconómica y las condiciones externas han favorecido a la región en el período. En términos más específicos, en las economías del Cono Sur, por ejemplo, la institucionalidad laboral a través del salario mínimo y la negociación colectiva ha contribuido de manera significativa (véase, por ejemplo, Maurizio y Vázquez, 2016). En las economías de América Central, las fuentes de ingresos no laborales y, en particular, las remesas, han tenido un impacto igualador en algunos casos (Acosta y otros, 2008). Más en general, las transferencias no contributivas a hogares con niños y las pensiones no contributivas contribuyeron al descenso de la desigualdad en el decenio anterior.

Dada la heterogeneidad de América Latina, resulta de interés analizar en detalle los movimientos observados en las subregiones que la componen. Con ese fin, se consideran cinco regiones: América Central, Región Andina, Cono Sur, México y el Brasil. Estos dos últimos países se separan por el fuerte peso que tienen en la región, tanto en términos de población como de ingresos. Como ya se señaló en la sección I, el índice de Gini de la región muestra que los ingresos de los latinoamericanos se tornan cada vez menos desiguales, aunque la reducción de la desigualdad se desacelera al final del período. Los movimientos regionales responden fundamentalmente a lo acontecido en América del Sur, dado que tanto en México como en América Central hay un comportamiento diferente. En este sentido, cabe destacar que el importantísimo peso del Brasil en la región, tanto en términos de población (el $37 \%$ en 2014) como de ingresos (el $45 \%$ en el mismo año), hace que los movimientos que se observan en ese país influyan de forma significativa en el indicador agregado de América Latina.

América Central es la subregión más desigual en 2014, pero el Brasil lo era en 2002 (véase el gráfico 11). La magra mejoría de los indicadores de América Central, en un contexto de fuerte reducción de la desigualdad en las otras subregiones, provoca la caída de esta al último lugar. En el otro extremo, México es la subregión menos desigual de América Latina, seguida muy de cerca por el Cono Sur y la Región Andina. Más allá de la caída de la desigualdad en la región, se destaca también el acercamiento entre las subregiones, que son cada vez más parecidas en términos de desigualdad.

\section{Gráfico 11}

América Latina (16 países ${ }^{a}$ y subregiones:

índice de Gini de los ingresos per cápita, 2002, 2009 y 2014b

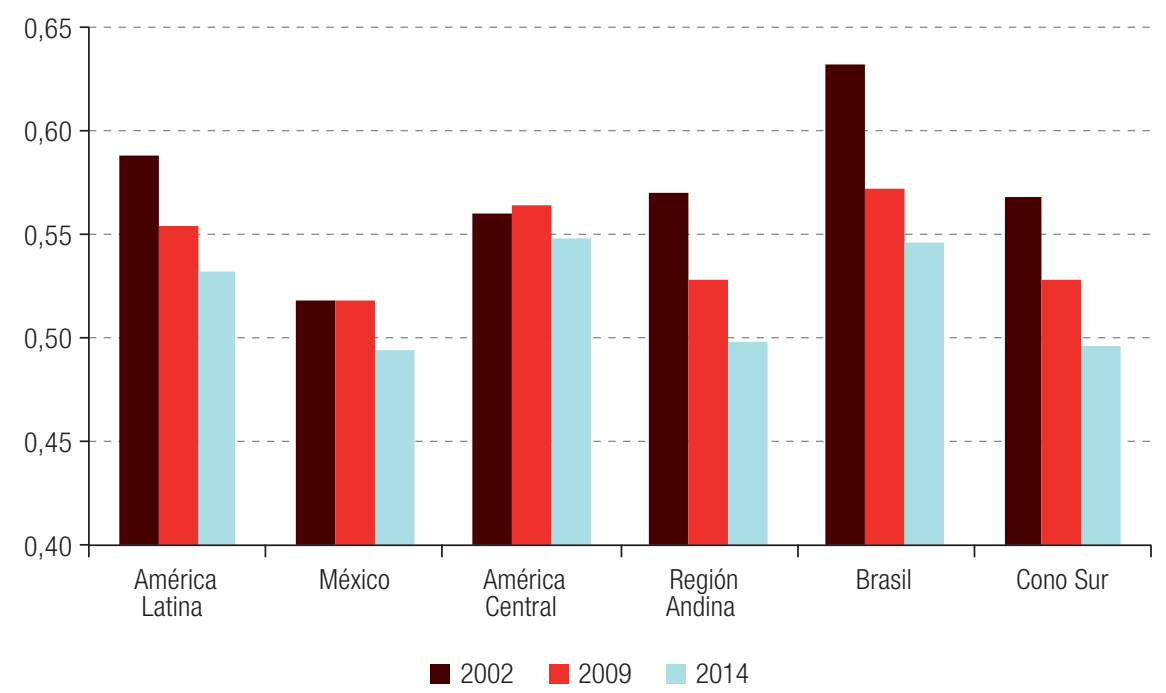

Fuente: Elaboración propia, sobre la base de encuestas de hogares.

a Argentina, Bolivia (Estado Plurinacional de), Brasil, Chile, Colombia, Costa Rica, Ecuador, El Salvador, Honduras, México, Panamá, Paraguay, Perú, República Dominicana, Uruguay y Venezuela (República Bolivariana de).

b En paridad del poder adquisitivo (PPA) de 2011. 
La variación del ingreso por percentil muestra patrones diferenciales por subperíodo y por subregión, que se presentan en el gráfico 12. En un grupo se destacan la Región Andina, el Brasil y el Cono Sur, que exhiben un alto nivel de crecimiento del ingreso en todos los percentiles y una pendiente negativa, lo que beneficia a los hogares más pobres y promueve una reducción de la desigualdad. En el segundo grupo se encuentran México y América Central, con un nivel de crecimiento menor que es levemente favorable a los pobres en el caso de México y no tiene efectos distributivos en América Central (su curva es casi horizontal). La Región Andina presenta los movimientos más similares entre los subperíodos, aunque con un nivel mayor al principio del período. Se observa un fuerte crecimiento del ingreso promedio de los sectores de menores ingresos, en especial del primer decil. Entre el primer decil y el último ventil, el crecimiento es uniforme en términos relativos y presenta un nivel significativamente menor entre los más ricos. En el caso del Brasil, se observa un gran crecimiento de las capas bajas y medias. Ambos subperíodos presentan esta forma, aunque en el caso del que va de 2002 a 2009, el crecimiento del ingreso es menor en el último ventil. En el Cono Sur se observa un crecimiento importante, el mayor entre las subregiones, aunque con un perfil menos igualitario que en otras. Por último, México es la única subregión que presenta una caída del ingreso en ambos subperíodos, si bien es más masiva en el segundo. Sin embargo, entre los más pobres, el segundo subperíodo resulta más provechoso: mientras que en el período de 2002 a 2009, el crecimiento del ingreso promedio de los más pobres es inferior al promedio, entre 2009 y 2014 es considerablemente superior, lo que da como resultado un crecimiento mayor que la media en el período completo.

\section{Gráfico 12}

América Latina (16 paísesa ${ }^{a}$ y subregiones: variación anual equivalente del ingreso per cápita por percentil, 2002-2014, 2002-2009 y 2009-2014b

(En porcentajes)

\section{A. América Latina}

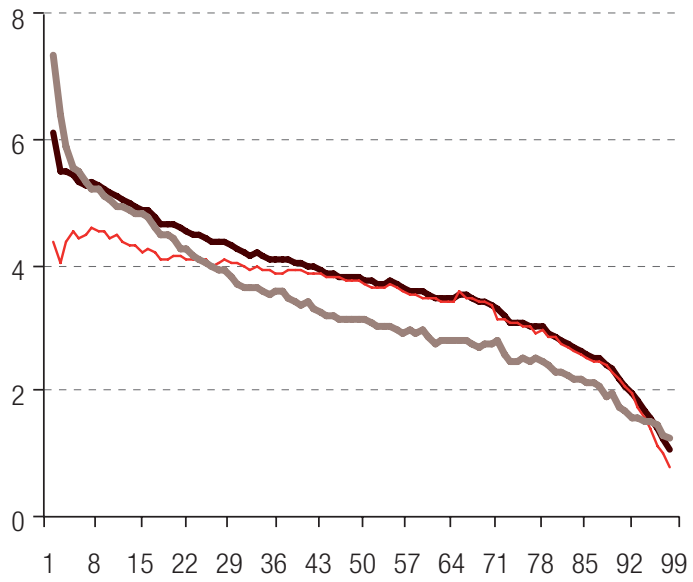

B. México

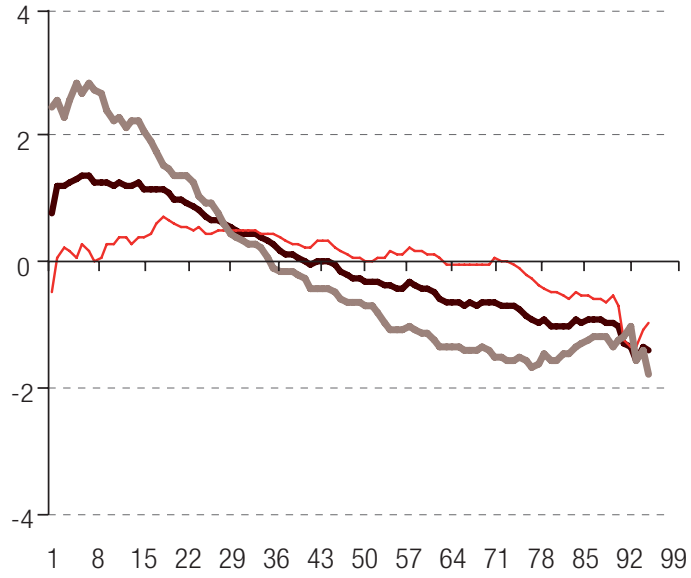


Gráfico 12 (conclusión)

C. América Central
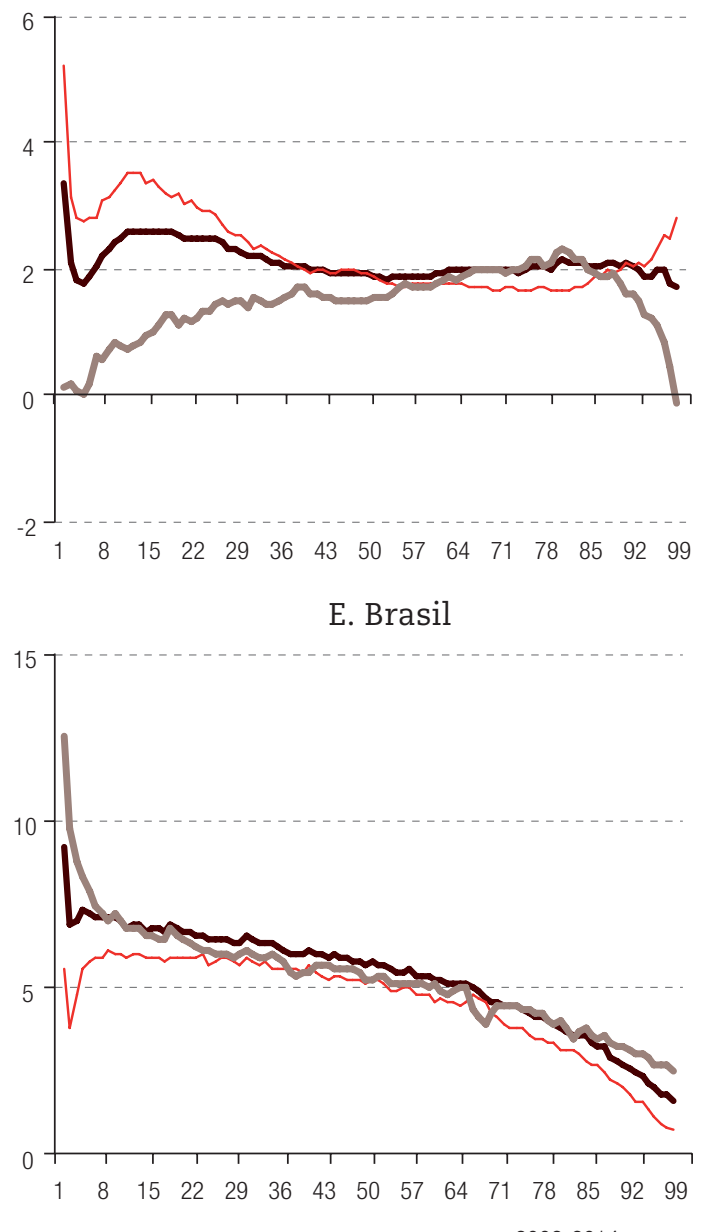

2002-2014
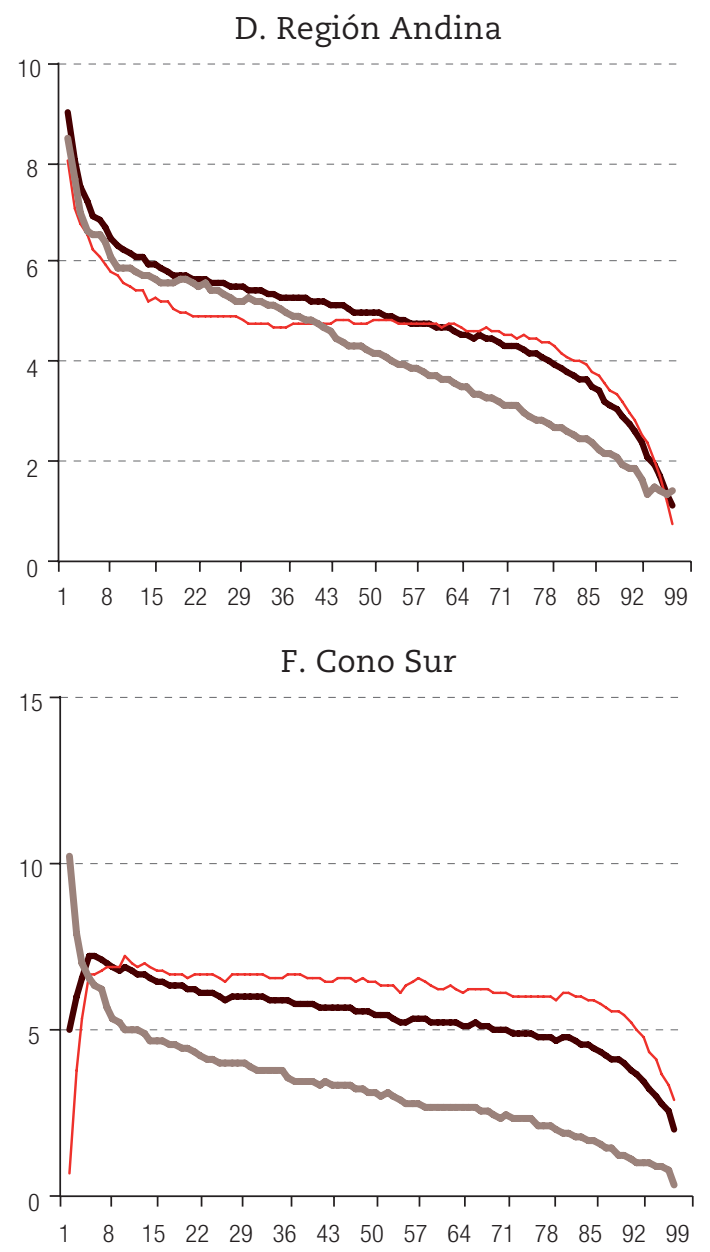

2002-2009 2009-2014

Fuente: Elaboración propia, sobre la base de encuestas de hogares.

a Argentina, Bolivia (Estado Plurinacional de), Brasil, Chile, Colombia, Costa Rica, Ecuador, El Salvador, Honduras, México, Panamá, Paraguay, Perú, República Dominicana, Uruguay y Venezuela (República Bolivariana de).

b Curvas de incidencia del crecimiento; en paridad del poder adquisitivo (PPA) de 2011.

Resulta interesante analizar también las curvas de variación del ingreso en términos absolutos. Como se discutiera en CEPAL (2014b), hay dos conceptos diferentes que subyacen a la noción de desigualdad del ingreso y que implican dos juicios de valor diferentes. Uno se refiere a la desigualdad relativa, que depende de las diferencias proporcionales en el ingreso, mientras que el otro hace referencia a las brechas del ingreso en términos absolutos y suele denominarse desigualdad absoluta. La distinción entre una y otra se ha perdido casi totalmente en los estudios empíricos actuales sobre desigualdad, que se concentran en el concepto relativo, aunque en la literatura sobre medición de la desigualdad de 
la última década se ha discutido sobre la cuantificación de la desigualdad absoluta (véanse Chakravarty y Tyagarupananda, 2009; Bosmans y Cowell, 2010). Si pensamos en términos de desigualdad absoluta, esta solo permanecerá incambiada si los ingresos de los hogares varían en el mismo monto (no en proporción), lo que es una condición sumamente exigente. Si la magnitud del ingreso de los individuos más ricos varía más, la desigualdad absoluta se incrementará. Es claro que resulta mucho más probable que la desigualdad se incremente cuando se considera la absoluta. Entre ambas visiones, no hay una que sea correcta o mejor que la otra desde el punto de vista teórico, sino que ambas son aceptables y la elección es, en última instancia, valorativa (Ravallion, 2004; Atkinson y Brandolini, 2010).

En el gráfico 13 se presentan las curvas de incidencia del crecimiento (GIC) que antes se analizaron en términos relativos, junto con las mismas variaciones en términos absolutos. En el caso de las curvas absolutas, la variación del ingreso es creciente en todas las subregiones, salvo en el caso de México ${ }^{15}$. Esto implica que, en los percentiles más ricos de todas las subregiones, el ingreso se incrementó más que en los más pobres en términos absolutos, aun cuando estas variaciones representan un porcentaje mayor del ingreso de los más pobres que de los más ricos. La desigualdad absoluta ha aumentado en las subregiones de América Latina.

\section{Gráfico 13}

América Latina (16 paísesa) y subregiones: variación relativa y absoluta del ingreso per cápita por percentil, 2002-2014b (En porcentajes y en dólares PPAc de 2011)

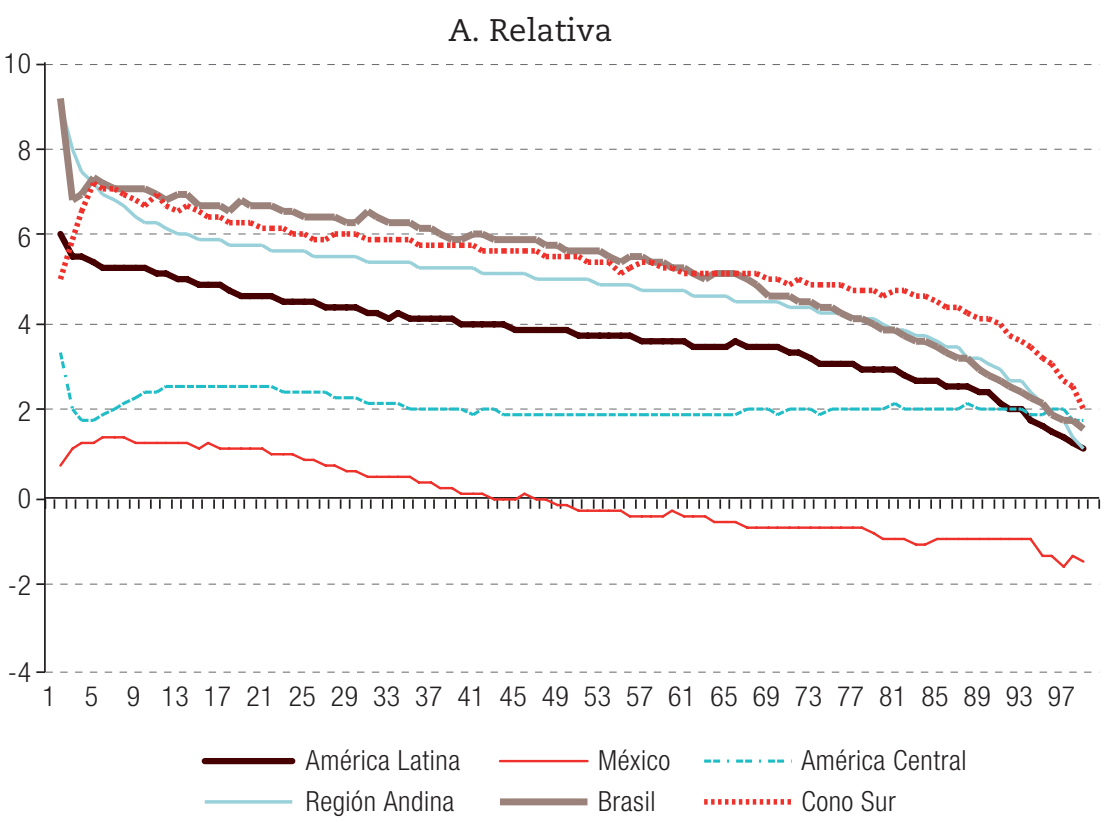

\footnotetext{
${ }^{15}$ En México se observa una caída del ingreso absoluto de los perceptores de altos ingresos, que se corrobora si se analizan las variaciones entre los años 2012 y 2013, y se modifica el punto de partida a 2000. Sin embargo, la caída del ingreso es mayor y más generalizada si se toma el 2014 (en ese año, se presenta desde la mediana, mientras que, en 2012 y 2013 , se observa en el último ventil). No se dispone de encuestas más recientes que permitan distinguir si esto se debe a un problema de la encuesta o a una caída más generalizada del ingreso en 2014. Sin desconocer estos elementos, debemos señalar que, para comprender los factores determinantes de este movimiento, se requiere un estudio más profundo.
} 
Gráfico 13 (conclusión)

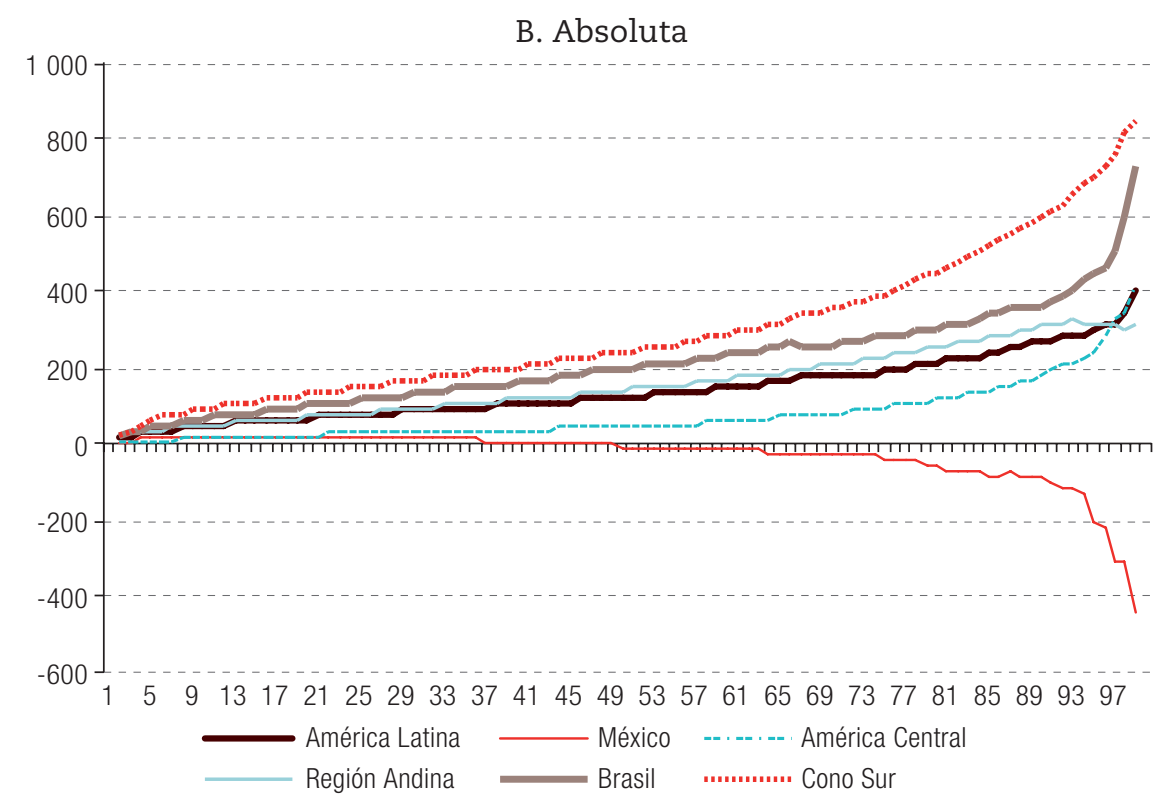

Fuente: Elaboración propia, sobre la base de encuestas de hogares.

a Argentina, Bolivia (Estado Plurinacional de), Brasil, Chile, Colombia, Costa Rica, Ecuador, El Salvador, Honduras, México, Panamá, Paraguay, Perú, República Dominicana, Uruguay y Venezuela (República Bolivariana de).

b Curvas de incidencia del crecimiento; variación relativa anual equivalente.

c Paridad del poder adquisitivo.

Los diferentes movimientos observados en las subregiones determinan cambios en la participación de estas en los deciles de ingresos de la región en su conjunto. En el gráfico 14 se calculan los deciles de ingresos de toda la población de la región y luego se analiza la participación de cada subregión en ellos. El Brasil tiene siempre la mayor participación en todos los deciles, aunque esta aumenta en los deciles superiores en 2014. México, a la inversa, pierde participación en los últimos niveles de ingreso y se corre hacia los sectores bajos y medios. La Región Andina presenta movimientos menores: su participación retrocede en el primer decil y aumenta levemente en los últimos cuatro. La participación del Cono Sur en los ingresos más altos de la región presenta un gran crecimiento relativo, mientras que la participación de América Central aumenta entre el 20\% más pobre.

La región ha enfrentado una desaceleración de su crecimiento económico durante los últimos años y, como consecuencia de ello, en 2015 los mercados laborales han comenzado a mostrar signos de debilidad en la creación de empleo, pérdida de dinamismo y un incremento del desempleo (CEPAL/OIT, 2016). No parece factible esperar que estos mercados laborales más tensionados y con contextos macroeconómicos menos favorables sigan impulsando nuevos descensos de la desigualdad y, de hecho, el nivel de desigualdad de las economías de América Latina en 2014 no difiere significativamente del correspondiente al año anterior (CEPAL, 2016). Esta es una señal clara del estancamiento del proceso de descenso que se verificaba en los años anteriores. Tampoco parece factible esperar que la desigualdad vuelva a descender a impulsos de la expansión de las transferencias monetarias. Por un lado, estas ya tienen una amplia cobertura en los países de América Latina y, por el otro, debido a las restricciones fiscales que enfrenta la región, no parecen estar dadas las condiciones para que se incrementen sus montos, a pesar de que estos no son abundantes y, por tanto, son poco redistributivos, como se señala en Amarante y Brun (2016). 


\section{Gráfico 14}

América Latina (cinco subregiones):

participación en los deciles de ingresos per cápita, 2002 y 2014ª

(En porcentajes)

\section{A. 2002}

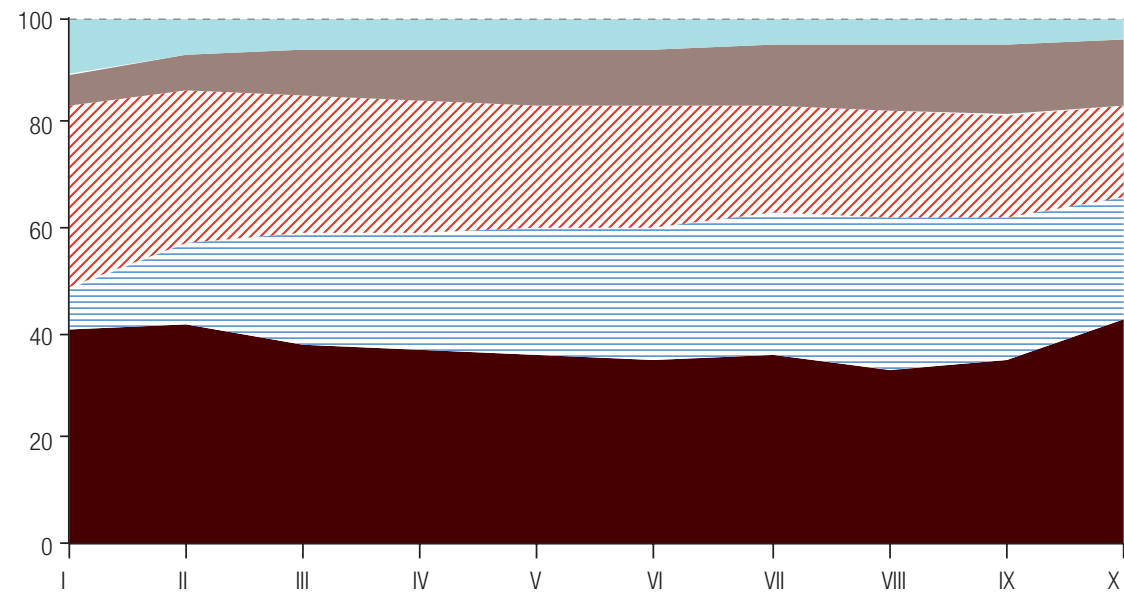

B. 2014

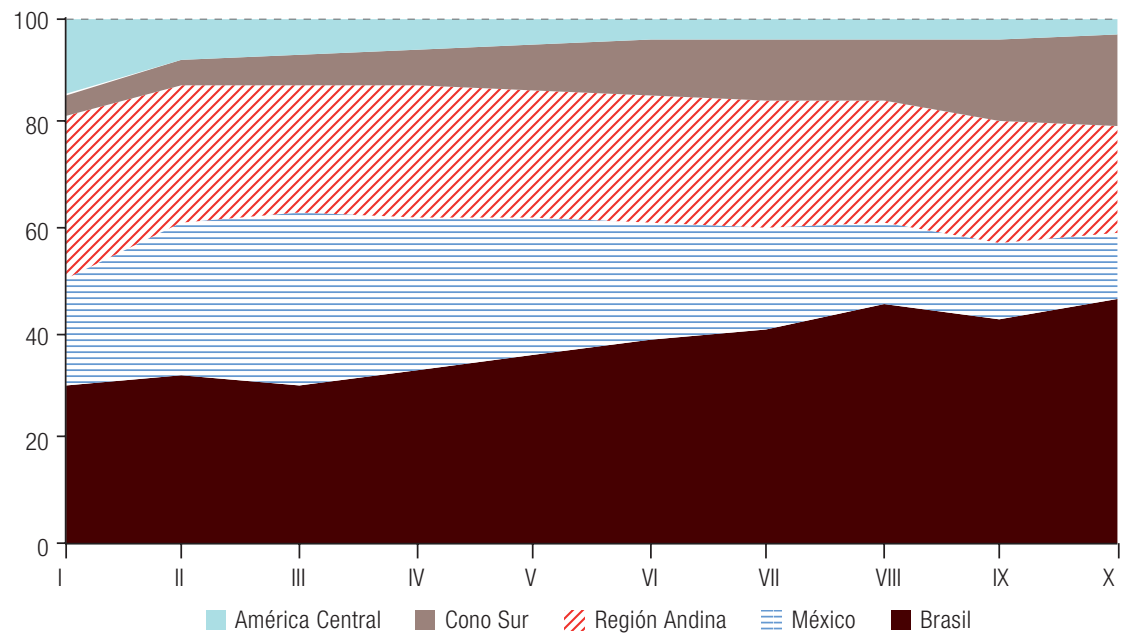

Fuente: Elaboración propia, sobre la base de encuestas de hogares.

a En paridad del poder adquisitivo (PPA).

En un trabajo reciente de Székely y Mendoza (2015), se recuerda que la suerte de la región, incluso en las dimensiones más vinculadas con el desarrollo social, aparece fuertemente ligada a la dependencia de las fluctuaciones de los precios que se deriva de la especialización productiva, y el reciente ciclo de descenso de la desigualdad parece reafirmarlo. La mayor igualdad de ingresos que se logró en los últimos años, sobre todo al potenciar la demanda de trabajadores de baja calificación y por tanto sus salarios, es sin duda una buena noticia porque implica la mejora de la calidad de vida de millones de personas en la región. Pero esta no parece haberse insertado aún en un proceso genuino de aumento de la productividad que dé sostenibilidad al incremento de la igualdad que se necesita en el largo plazo. Una vez más, la integración de las esferas social y productiva de las políticas públicas aparece como tarea pendiente. 


\section{Comentarios finales}

La desigualdad a nivel global no se ha incrementado en las últimas décadas. Por el contrario, tenemos ahora evidencia de calidad que nos indica que las condiciones de vida de los ciudadanos del mundo se han vuelto, en todo caso, más igualitarias, debido sobre todo al importante crecimiento de los ingresos de la población de China y, en menor medida, de la India. Sin embargo, al mismo tiempo, en el interior de la mayoría de los países, el nivel de desigualdad del ingreso se ha visto incrementado, especialmente en los países en desarrollo. Entre las distintas fuerzas que pueden estar impulsando esta mayor dispersión de los ingresos se cuentan la globalización y los procesos de liberalización comercial, que se producen junto con los avances tecnológicos y cuyos efectos son difíciles de aislar. La creciente importancia del sector financiero y la concentración del retorno del capital también fortalecen el proceso de concentración del ingreso.

Una de las excepciones a este incremento generalizado de la desigualdad ha sido América Latina en el último decenio, ya que, tanto a nivel de la región considerada en su conjunto como en el plano de las experiencias nacionales, se detecta un importante descenso de los indicadores de desigualdad del ingreso. Se han combinado factores favorables del contexto macroeconómico regional que no pueden desconocerse, como el incremento de los precios de los productos básicos, que ha dinamizado los mercados laborales de la región, impulsado la demanda de trabajo no calificado e incrementado los salarios de la parte baja de la distribución. Pero también han operado factores institucionales, con una fuerza diferencial que depende de cada país. Se ha dado un mayor impulso a las políticas redistributivas, como las transferencias monetarias no contributivas a hogares con niños o adultos mayores, o el fortalecimiento de las instituciones laborales, como el salario mínimo o la negociación colectiva. Las últimas cifras disponibles han comenzado a mostrar signos de una desaceleración del crecimiento económico y el dinamismo de los mercados laborales, así como también de un estancamiento en el proceso de descenso de la desigualdad. Está abierta por lo tanto la pregunta de en qué medida la región será capaz de proteger los importantes logros que se han alcanzado en términos de mayor igualdad de ingresos y, más aún, si será capaz de retomar esa senda de avance hacia una mayor igualdad.

\section{Bibliografía}

Acosta, P. y otros (2008), "What is the impact of international remittances on poverty and inequality in Latin America?", World Development, vol. 36, № 1, Amsterdam, Elsevier.

Alvaredo, F. y L. Gasparini (2015), "Recent trends in inequality and poverty in developing countries", Handbook of Income Distribution, A. Atkinson y F. Bourguignon (eds.), vol. 2, Amsterdam, Elsevier.

Amarante, V. y M. Brun (2016), "Cash transfers in Latin America: effects on poverty and redistribution", WIDER Working Paper, N² 2016/136, Helsinki, Instituto Mundial de Investigaciones de Economía del Desarrollo (UNU-WIDER).

Amarante, V., M. Galván y X. Mancero (2016), "Desigualdad en América Latina: una medición global”, Revista CEPAL, № 118 (LC/G.2676-P), Santiago, Comisión Económica para América Latina y el Caribe (CEPAL).

Anand, S. y P. Segal (2015), "The global distribution of income", Handbook of Income Distribution, A. Atkinson y F. Bourguignon (eds.), vol. 2, Amsterdam, Elsevier.

(2008), "What do we know about global income inequality?", Journal of Economic Literature, vol. 46, $N^{\circ}$ 1, Nashville, Tennessee, American Economic Association.

Atkinson, A. B. y A. Brandolini (2010), "On analyzing the world distribution of income", World Bank Economic Review, vol. 24, № 1, Washington, D.C., Banco Mundial.

Atkinson, A. B. y S. Morelli (2014), "Chartbook of economic inequality", ECINEQ Working Paper Series, № 2014-324, Sociedad para el Estudio de la Desigualdad Económica (ECINEQ). 
Atkinson, A. B., T. Piketty y E. Sáez (2011), "Top incomes in the long run of history", Journal of Economic Literature, vol. 49, № 1, Nashville, Tennessee, American Economic Association.

Banco Mundial (2015), Purchasing Power Parities and the Real Size of World Economies. A Comprehensive Report of the 2011 International Comparison Program, Washington, D.C.

Bartolini, S. y F. Sarracino (2014), "The dark side of Chinese growth: explaining decreasing well-being in times of economic boom", MPRA Paper, № 57765 [en línea] https://mpra.ub.uni-muenchen.de/57765/1/ MPRA_paper_57765.pdf.

Bosmans, K. y F. A. Cowell (2010), "The class of absolute decomposable inequality measures", Economics Letters, vol. 109, № 3, Amsterdam, Elsevier.

Bourguignon, F. (2015), The Globalization of Inequality, Princeton, Princeton University Press.

Brockmann, H. y otros (2009), "The China puzzle: falling happiness in a rising economy", Journal of Happiness Studies, vol. 10, № 4, Springer.

CEPAL (Comisión Económica para América Latina y el Caribe) (2016), Panorama Social de América Latina, 2015 (LC/G.2691-P), Santiago. (2014a), Pactos para la igualdad: hacia un futuro sostenible (LC/G.2586(SES.35/3)), Santiago. (2014b), Panorama Social de América Latina, 2014 (LC/G.2635-P), Santiago.

CEPAL/OIT (Comisión Económica para América Latina y el Caribe/Organización Internacional del Trabajo) (2016), Coyuntura Laboral en América Latina y el Caribe, № 14 (LC/L.4141), Santiago.

Chakravarty, S. R. y S. Tyagarupananda (2009), "The subgroup decomposable intermediate indices of inequality", Spanish Economic Review, vol. 11, № 2, Springer.

Cord, L. y otros (2016), "Inequality stagnation in Latin America in the aftermath of the global financial crisis", Review of Development Economics, vol. 21, № 1, Wiley.

Cornia, G. (ed.) (2014), Falling Inequality in Latin America. Policy Changes and Lessons, Oxford, Oxford University Press.

Dollar, D. (2007), "Poverty, inequality, and social disparities during China's economic reform”, Policy Research Working Paper, № 4253, Washington, D.C., Banco Mundial.

Gasparini, L. y otros (2012), "Educational upgrading and returns to skills in Latin America: evidence from a supply-demand framework, 1990-2010”, Documento de Trabajo, № 127, La Plata, Centro de Estudios Distributivos, Laborales y Sociales (CEDLAS).

Gasparini, L. y P. Gluzmann (2012), "Estimating income poverty and inequality from the Gallup World Poll: the case of Latin America and the Caribbean", Journal of Income Distribution, vol. 21, № 1.

Hauser, S. M. e Y. Xie (2005), "Temporal and regional variation in earnings inequality: urban China in transition between 1988 and 1995", Social Science Research, vol. 34, № 1, Amsterdam, Elsevier.

Jansen, W. y X. Wu (2012), "Income inequality in urban China, 1978-2005", Chinese Sociological Review, vol. 45, № 1, Taylor \& Francis.

Lakner, C. y B. Milanovic (2016), "Global income distribution: from the fall of the Berlin Wall to the Great Recession", World Bank Economic Review, vol. 30, №2, Washington, D.C., Banco Mundial.

Maurizio, R. y G. Vázquez (2016), "Distribution effects of the minimum wage in four Latin American countries: Argentina, Brazil, Chile and Uruguay", International Labour Review, vol. 155, № 1, Wiley.

Meng, X., K. Shen y S. Xue (2013), "Economic reform, education expansion, and earnings inequality for urban males in China, 1988-2009", Journal of Comparative Economics, vol. 41, № 1, Amsterdam, Elsevier.

Milanovic, B. (2016), Global Inequality: A New Approach for the Age of Globalization, Cambridge, Massachusetts, Harvard University Press. (2005), Worlds Apart: Global and International Inequality 1950-2000, Princeton, Princeton University Press.

Morelli, S., T. M. Smeeding y J. P. Thompson (2015), "Post-1970 trends in within-country inequality and poverty: rich and middle income countries", Handbook of Income Distribution, A. Atkinson y F. Bourguignon (eds.), vol. 2, Amsterdam, Elsevier.

Niño-Zarazúa, M., L. Roope y F. Tarp (2014), "Global interpersonal inequality: trends and measurement", WIDER Working Paper, № 2014/004, Helsinki, Instituto Mundial de Investigaciones de Economía del Desarrollo (UNU-WIDER).

OCDE (Organización de Cooperación y Desarrollo Económicos) (2011), Divided We Stand: Why Inequality Keeps Rising, París, OECD Publishing.

Piketty, T. (2014), El capital en el siglo XXI, Madrid, Fondo de Cultura Económica.

Piketty, T. y E. Sáez (2013), "Top incomes and the great recession: recent evolutions and policy implications", IMF Economic Review, vol. 61, №3, Washington, D.C., Fondo Monetario Internacional. 
Ravallion, M. (2004), "Competing concepts of inequality in the globalization debate", Policy Research Working Paper, No 3243, Washington, D.C., Banco Mundial.

Ravallion, M. y S. Chen (2003), "Measuring pro-poor growth", Economic Letters, vol. 78, N 1, Amsterdam, Elsevier.

Ruiz, N. y N. Woloszko (2016), "What do household surveys suggest about the top 1 incomes and inequality in OECD countries?", OECD Economics Department Working Papers, № 1265, París, OECD Publishing.

Sicular, T. y otros (2007), "The urban-rural income gap and inequality in China", Review of Income and Wealth, vol. 53, № 1 , Wiley.

Székely, M. y P. Mendoza (2015), "Is the decline in inequality in Latin America here to stay?", Journal of Human Development and Capabilities, vol. 16, № 3, Taylor \& Francis.

Tao Yang, D. y H. Zhou (1999), "Rural-urban disparity and sectoral labour allocation in China", The Journal of Development Studies, vol. 35, № 3, Taylor \& Francis.

Xie, Y. y X. Zhou (2014), "Income inequality in today's China", Proceedings of the National Academy of Sciences, vol. 111, N 19, National Academy of Sciences.

Zhou, X. (2014), "Increasing returns to education, changing labor force structure and the rise of earnings inequality in urban China, 1996-2010", Social Forces, vol. 93, № 2, Oxford University Press. 


\section{Anexo A1}

\section{Cuadro A1.1}

América Latina (16 países): encuestas utilizadas para determinar la desigualdad regional

\begin{tabular}{llll}
\hline País & 2002 & 2009 & 2014 \\
\hline Argentina & 2002 & 2009 & 2012 \\
\hline Bolivia (Estado Plurinacional de) & 2002 & 2009 & 2013 \\
\hline Brasil & 2002 & 2009 & 2014 \\
\hline Chile & 2003 & 2009 & 2013 \\
\hline Colombia & 2002 & 2009 & 2014 \\
\hline Costa Rica & 2002 & 2009 & 2014 \\
\hline Ecuador & 2002 & 2009 & 2014 \\
\hline El Salvador & 2001 & 2009 & 2014 \\
\hline Honduras & 2002 & 2009 & 2010 \\
\hline México & 2002 & 2008 & 2014 \\
\hline Panamá & 2002 & 2009 & 2014 \\
\hline Perú & 2001 & 2009 & 2014 \\
\hline Paraguay & 2001 & 2009 & 2014 \\
\hline República Dominicana & 2002 & 2009 & 2014 \\
\hline Uruguay & 2002 & 2009 & 2014 \\
\hline Venezuela (República Bolivariana de) & 2002 & 2009 & 2013 \\
\hline Fuen
\end{tabular}

Fuente: Elaboración propia, sobre la base de encuestas de hogares.

\section{Cuadro A1.2}

América Latina (16 países): peso de cada país en los ingresos y en la población (En porcentajes)

\begin{tabular}{|c|c|c|c|c|c|c|}
\hline \multirow[b]{2}{*}{ País } & \multicolumn{2}{|c|}{2002} & \multicolumn{2}{|c|}{2009} & \multicolumn{2}{|c|}{2014} \\
\hline & Población & $\begin{array}{c}\text { Ingresos } \\
\text { (PPA) }\end{array}$ & Población & $\begin{array}{l}\text { Ingresos } \\
\text { (PPA) }\end{array}$ & Población & $\begin{array}{c}\text { Ingresos } \\
\text { (PPA) }\end{array}$ \\
\hline Argentina & 5,4 & 6,4 & 4,8 & 8,5 & 4,7 & 7,5 \\
\hline Bolivia (Estado Plurinacional de) & 1,9 & 1,0 & 2,0 & 1,2 & 2,0 & 1,2 \\
\hline Brasil & 37,4 & 41,6 & 37,6 & 41,8 & 37,2 & 43,3 \\
\hline Chile & 3,4 & 4,1 & 3,3 & 4,0 & 3,2 & 4,2 \\
\hline Colombia & 8,7 & 5,5 & 8,6 & 5,7 & 8,5 & 6,1 \\
\hline Costa Rica & 0,9 & 0,9 & 0,9 & 0,9 & 0,9 & 0,9 \\
\hline Ecuador & 1,8 & 1,3 & 2,8 & 1,6 & 3,0 & 1,8 \\
\hline El Salvador & 1,5 & 0,6 & 1,6 & 0,6 & 1,5 & 0,5 \\
\hline Honduras & 22,3 & 23,3 & 21,2 & 19,0 & 22,0 & 18,1 \\
\hline México & 0,7 & 0,6 & 0,7 & 0,6 & 0,7 & 0,7 \\
\hline Panamá & 1,2 & 0,9 & 1,2 & 0,8 & 1,2 & 1,1 \\
\hline Perú & 5,9 & 3,2 & 6,0 & 3,8 & 5,8 & 4,0 \\
\hline Paraguay & 1,8 & 1,6 & 1,9 & 1,7 & 1,9 & 1,5 \\
\hline República Dominicana & 1,4 & 0,8 & 1,2 & 0,6 & 1,2 & 0,6 \\
\hline Uruguay & 0,6 & 0,8 & 0,7 & 0,9 & 0,6 & 0,9 \\
\hline Venezuela (República Bolivariana de) & 5,4 & 7,3 & 5,5 & 8,3 & 5,5 & 7,8 \\
\hline
\end{tabular}

Fuente: Elaboración propia, sobre la base de encuestas de hogares.

Nota: PPA significa paridad del poder adquisitivo. 